\title{
Neuronal BC RNA Transport Impairments Caused by Systemic Lupus Erythematosus Autoantibodies
}

\author{
Ilham A. Muslimov, ${ }^{1}$ Anna Iacoangeli, ${ }^{1}$ Taesun Eom, ${ }^{1}$ Anne Ruiz, ${ }^{1}$ Madisen Lee, ${ }^{1}$ Stacy Stephenson, ${ }^{2}$ Ellen M. Ginzler, ${ }^{3}$ \\ and ${ }^{-H e n r i ~ T i e d g e}{ }^{1,4}$ \\ ${ }^{1}$ The Robert F. Furchgott Center for Neural and Behavioral Science, Department of Physiology and Pharmacology, ${ }^{2}$ Division of Comparative Medicine, \\ ${ }^{3}$ Division of Rheumatology, Department of Medicine, and ${ }^{4}$ Department of Neurology, State University of New York Downstate Medical Center, Brooklyn, \\ New York 11203
}

The etiology of the autoimmune disorder systemic lupus erythematosus (SLE) remains poorly understood. In neuropsychiatric SLE (NPSLE), autoimmune responses against neural self-antigens find expression in neurological and cognitive alterations. SLE autoantibodies often target nucleic acids, including RNAs and specifically RNA domains with higher-order structural content. We report that autoantibodies directed against neuronal regulatory brain cytoplasmic (BC) RNAs were generated in a subset of SLE patients. By contrast, anti-BC RNA autoantibodies (anti-BC abs) were not detected in sera from patients with autoimmune diseases other than SLE (e.g., rheumatoid arthritis or multiple sclerosis) or in sera from healthy subjects with no evidence of disease. SLE anti-BC abs belong to the IgG class of immunoglobulins and target both primate BC200 RNA and rodent BC1 RNA. They are specifically directed at architectural motifs in BC RNA 5' stem-loop domains that serve as dendritic targeting elements (DTEs). SLE anti-BC abs effectively compete with RNA transport factor heterogeneous nuclear ribonucleoprotein A2 (hnRNP A2) for DTE access and significantly diminish BC RNA delivery to synapto-dendritic sites of function. In vivo experiments with male BALB/c mice indicate that, upon lipopolysaccharide-induced opening of the blood-brain barrier, SLE anti-BC abs are taken up by CNS neurons where they significantly impede localization of endogenous BC1 RNA to synapto-dendritic domains. Lack of BC1 RNA causes phenotypic abnormalities including epileptogenic responses and cognitive dysfunction. The combined data indicate a role for anti-BC RNA autoimmunity in SLE and its neuropsychiatric manifestations.

Key words: anti-RNA antibodies; autoimmunity; dendritic RNA; lupus; neuronal regulatory RNAs

Significance Statement

Although clinical manifestations of neuropsychiatric lupus are well recognized, the underlying molecular-cellular alterations have been difficult to determine. We report that sera of a subset of lupus patients contain autoantibodies directed at regulatory brain cytoplasmic (BC) RNAs. These antibodies, which we call anti-BC abs, target the BC RNA 5' domain noncanonical motif structures that specify dendritic delivery. Lupus anti-BC abs effectively compete with RNA transport factor heterogeneous nuclear ribonucleoprotein A2 (hnRNP A2) for access to BC RNAs. As a result, hnRNP A2 is displaced, and BC RNAs are impaired in their ability to reach synapto-dendritic sites of function. The results reveal an unexpected link between BC RNA autoantibody recognition and dendritic RNA targeting. Cellular RNA dysregulation may thus be a contributing factor in the pathogenesis of neuropsychiatric lupus.

\section{Introduction}

Systemic lupus erythematosus (SLE) is a chronic autoimmune disorder of complex etiology. Neuropsychiatric SLE (NPSLE) is a

Received July 2, 2018; revised May 2, 2019; accepted June 24, 2019.

Author contributions: I.A.M., A.I., T.E., E.M.G., and H.T. designed research; I.A.M., A.I., T.E., A.R., M.L., S.S., and E.M.G. performed research; I.A.M., A.I., T.E., A.R., E.M.G., and H.T. analyzed data; I.A.M. and H.T. wrote the first draft of the paper; I.A.M., A.I., T.E., E.M.G., and H.T. edited the paper.

This work was supported by the National Institutes of Health (Grants DA026110 and NS046769 to H.T.). We thank Ellen Hsu for advice and discussion and Dimitre Stefanov for consultation on statistical approaches.

The authors declare no competing financial interests. severe subtype of SLE (Popescu and Kao, 2011; Zirkzee et al., 2012) in which a CNS with a compromised blood-brain barrier (BBB) is targeted by autoimmune antibodies (Abbott et al., 2003; Mader et al., 2017). Cognitive dysfunction and seizures are common disease manifestations (Mikdashi et al., 2005; Joseph et al.,

A. lacoangeli's present address: Tisch MS Research Center of New York, 521 West 57th Street, New York, New York 10019

Correspondence should be addressed to Henri Tiedge at henri.tiedge@downstate.edu.

https://doi.org/10.1523/JNEUROSCI.1657-18.2019

Copyright $\odot 2019$ the authors 
2007; Cimaz and Guerrini, 2008; Popescu and Kao, 2011; Mader et al., 2017).

A major gap in our understanding of SLE concerns the question how molecular autoimmune reactions give rise to the observed phenotypic alterations. SLE autoantibodies are often directed against nucleic acids or their binding proteins (Arbuckle et al., 2003; Elkon and Casali, 2008; Crow, 2010; Barrat et al., 2016). SLE anti-RNA autoantibodies typically target structured RNAs with double-stranded content (Schur and Monroe, 1969; Talal, 1973; Barrat et al., 2016). Examples of such autoantigens include ribosomal RNAs (rRNAs), e.g., 28S rRNA (Sturgill and Carpenter, 1965; Lamon and Bennett, 1970; Chu et al., 1991; Uchiumi et al., 1991; Elkon et al., 1992). Ribosomal RNAs form higher-order structural motifs, and it is mainly such motifs, rather than nucleotide sequence, that are recognized by ribosomal proteins (Noller, 2005; Grandin, 2010) and by autoimmune antibodies (Chu et al., 1991; Uchiumi et al., 1991). Similarly, higher-order structures in U1 spliceosomal RNA can trigger SLE autoimmune responses (van Venrooij et al., 1990; Hoet et al., 1999).

Regulatory brain cytoplasmic (BC) RNAs are non-proteincoding, small cytoplasmic RNAs (scRNAs) that, expressed in neurons, are located to synapto-dendritic domains (for review, see Iacoangeli and Tiedge, 2013; Eom et al., 2018). BC RNAs control local protein synthesis by interacting with eukaryotic initiation factors (eIFs) $4 \mathrm{~A}$ and $4 \mathrm{~B}$, thus repressing translation in the basal default state (Wang et al., 2002, 2005; Lin et al., 2008; Eom et al., 2011, 2014). After neuronal stimulation and receptor activation, translation is reversibly derepressed, effectively switching BC RNA translational control from a repressive to a permissive state (Eom et al., 2014). Responsible for translational control competence are C-loop architectural motifs in the BC RNA 3' domains (Lin et al., 2008; Eom et al., 2011). BC RNA 5' domains, in contrast, carry dendritic targeting elements (DTEs), spatial codes embedded in stem-loop noncanonical motif structures that specify targeted delivery to synapto-dendritic sites of function (Muslimov et al., 2006, 2011, 2018; Eom et al., 2018).

BC RNAs include rodent BC1 RNA and primate BC200 RNA which, although functionally analogous, are not phylogenetically orthologous as their genes have independently evolved in the rodent and primate lineages, respectively (Skryabin et al., 1998; Rozhdestvensky et al., 2001; Khanam et al., 2007; Iacoangeli and Tiedge, 2013; Eom et al., 2018). Thus, although BC1 and BC200 RNAs are unrelated in their primary structures (DeChiara and Brosius, 1987; Tiedge et al., 1993), higher-order-structure functional motif content is similar or identical, enabling the two RNAs to interact with the same protein factors in the execution of their cellular functions (Eom et al., 2011, 2018; Iacoangeli and Tiedge, 2013).

Here, we hypothesized that architectural motif structures in regulatory $\mathrm{BC}$ RNAs can become targets of autoimmune reactivity in SLE. We detected anti-BC RNA reactivity in sera of a subset of SLE patients, and we determined that SLE anti-BC RNA autoantibodies (anti-BC abs) are directed against DTE motif structures in 5' stem-loop domains. Anti-BC abs effectively compete with RNA transport factor heterogeneous nuclear ribonucleoprotein A2 (hnRNP A2) for access to these structures. After uptake by neurons in primary culture or CNS neurons in vivo, SLE anti-BC abs significantly diminish BC RNA delivery to synaptodendritic domains. Absence of BC1 RNA in the BC1 knock-out (KO) animal model causes epileptogenic susceptibility (Zhong et al., 2009, 2010) and cognitive dysfunction (Briz et al., 2017; Chung et al., 2017; Iacoangeli et al., 2017). Our work introduces a
Table 1. Autoimmune anti-BC RNA reactivity

\begin{tabular}{llllll}
\hline & & \multicolumn{2}{l}{ Anti-BC RNA reactivity } & \\
\cline { 3 - 5 } Subjects & Diagnosis & ++ & + & - & $n$ \\
\hline Group I & SLE with seizures & $10(36 \%)$ & 12 & 6 & 28 \\
Group II & SLE with OBS & $4(18 \%)$ & 13 & 5 & 22 \\
Group III & SLE & $4(21 \%)$ & 11 & 4 & 19 \\
Group IV & Healthy subjects & 0 & 0 & 17 & 17 \\
Group V & Rheumatoid arthritis & 0 & 0 & 8 & 8 \\
Group VI & Ulcerative colitis & 0 & 0 & 1 & 1 \\
Group VII & Multiple sclerosis & 0 & 0 & 12 & 12 \\
\hline
\end{tabular}

Reactivity is categorized as follows: ++ , strong reactivity; + , weak reactivity; - , no reactivity. Reactivity to $B C$ RNAs is specific to SLE patients (Groups I-III). Samples from healthy subjects with no evidence of disease (healthy subjects, Group IV) and samples from patients with autoimmune diseases other than SLE (i.e. RA, UC, MS; Groups $\mathrm{V}-\mathrm{VII}$ ) were found to be nonreactive. $n$ refers to the total number of subjects in each group. Anti-BC RNA reactivity was established by EMSA analysis using ${ }^{32}$ P-labeled BC200 RNA.

novel concept of SLE autoimmunity directed against regulatory BC RNAs.

\section{Materials and Methods}

Sera and antibodies. We collected sera from 69 patients diagnosed with SLE. These patients were categorized into three groups according to the criteria of the American College of Rheumatology for SLE (Tan et al., 1982) and for NPSLE (American College of Rheumatology, 1999). Sera were collected as follows (Table 1): Group I, SLE with seizure activity; Group II, SLE with organic brain syndrome (OBS); and Group III, SLE without diagnosed seizure or OBS involvement. Herein, SLE autoantibodies are identified by a patient code in which a number may be preceded by the letters $S$ (indicating an SLE patient with a history of seizures) or OBS (indicating an SLE patient with organic brain syndrome). SLE patients with no history of seizures or OBS are identified by numbers without preceding letters.

In addition, sera from non-SLE human subjects were collected as follows: Group IV, healthy with no evidence of disease (healthy subjects, HS); Group V, rheumatoid arthritis (RA); Group VI, ulcerative colitis (UC); and Group VII, multiple sclerosis (MS). SLE and UC sera were obtained from patients at the Division of Rheumatology of SUNY Downstate Medical Center (DMC). Samples were collected during periods of active disease when patients reported to the clinic. Clinical staff participating in sample collection were not cognizant of subsequent experimental sample usage (i.e., they were "blinded"). Samples were deidentified and end-point experimenters were not cognizant of sample types at the time of experimentation. The study was approved by the institutional review board of SUNY DMC and informed consent was obtained from all patients. Serum samples from HS, patients with RA, and patients with MS were obtained from Valley Biomedical and Proteogenex.

IgG was purified from human subject sera in a two-step protocol. In a first step, using a Nab Spin Kit (Thermo Fisher Scientific), serum samples were incubated in binding buffer on a Protein A/G spin column for 10 min. The column was washed with $400 \mu \mathrm{l}$ of Nab Spin binding buffer at least three times. Antibodies were eluted from the column, using $400 \mu \mathrm{l}$ of Nab Spin elution buffer, in three consecutive steps (elution 1-3). The three elution fractions were analyzed by SDS PAGE. In a second step, we used a NAb Protein G Spin Kit (Thermo Fisher Scientific) to purify IgG by removing any residual IgM. Elution 1 from step 1 was incubated in binding buffer on a Protein $\mathrm{G}$ spin column for $10 \mathrm{~min}$. The column was washed with $400 \mu \mathrm{l}$ of Nab Spin binding buffer three times. IgG was eluted from the column using $400 \mu \mathrm{l}$ of Nab Spin elution buffer. IgG samples were dialyzed overnight at $4^{\circ} \mathrm{C}$ against PBS in Slide-A-Lyzer dialysis cassettes (Thermo Fisher Scientific). Samples were analyzed by SDS PAGE. Samples from step 2 were used for electrophoretic mobility shift assay (EMSA) analysis and RNA transport analysis. Samples from step 1 (elution 1) were also used for EMSA analysis.

DNA synthesis and labeling. BC200 DNA was synthesized by PCR from plasmid pBC200 (Kondrashov et al., 2005) using primers as follows: BC200 forward primer, GGC CGG GCG CGG TGG CTCA; BC200 reverse primer, GGG GGG TTG TTG CTT TGA GGG. Synthesis and labeling was done using the Platinum PCR SuperMix (Thermo Fisher 
A

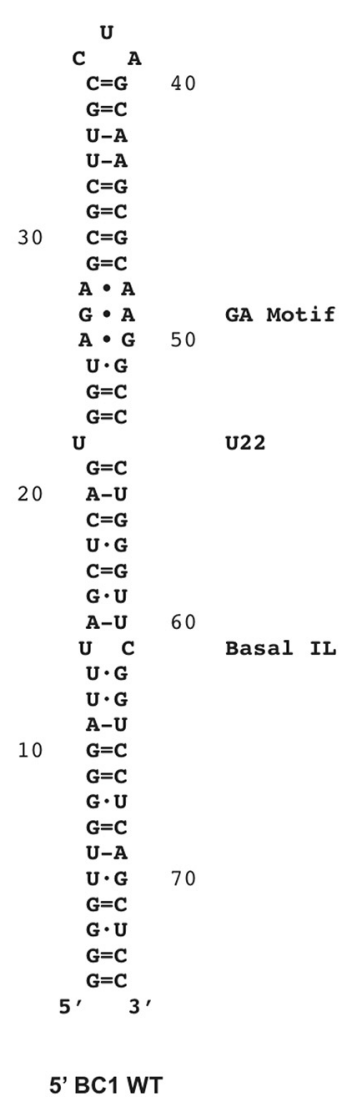

B

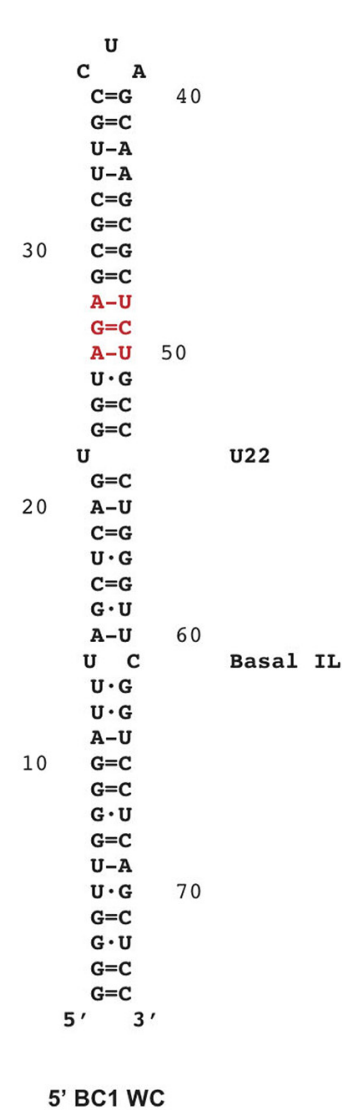

C

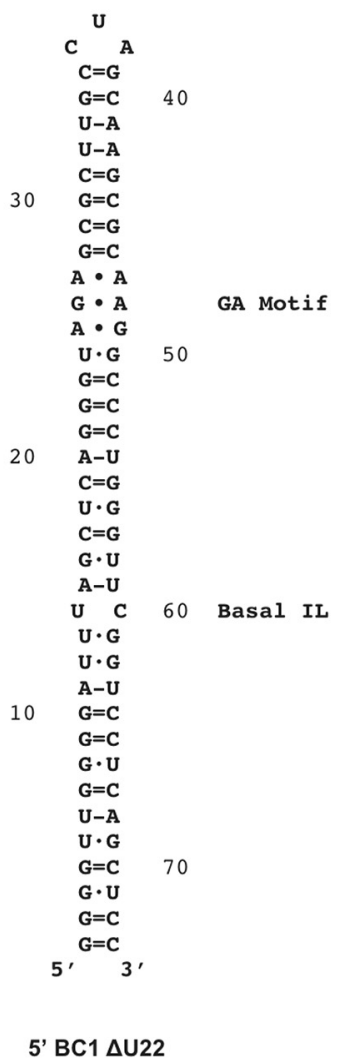

D

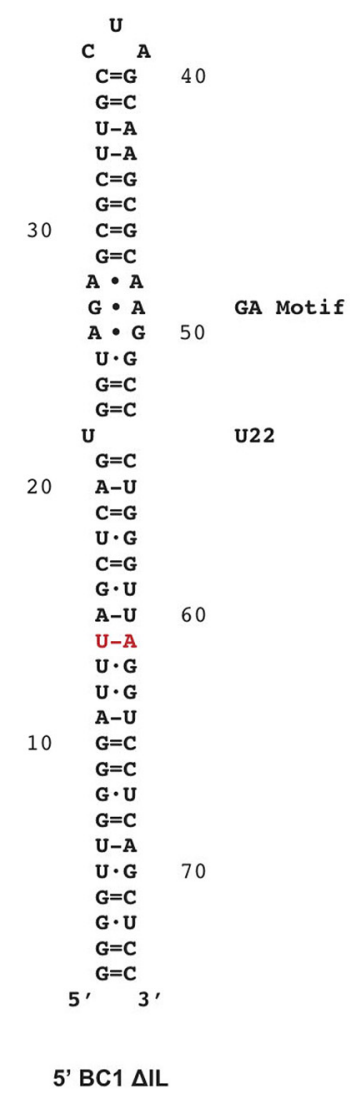

Figure 1. Secondary structures of WT and mutant 5' BC1 domains. A, Secondary structure of the WT 5' BC1 domain was established by chemical and enzymatic probing (Rozhdestvensky et al., 2001). GA motif, unpaired U22, and the basal internal loop (IL) are indicated. Noncanonical purine-purine pairs are symbolized by $\bullet$, standard WC pairs by $=(\mathrm{GC})$ or $-(\mathrm{AU})$, wobble W( pairs by $\cdot$ The noncanonical GA core motif resides in an A-form helix in the $5^{\prime}$ BC1 stem-loop domain (Muslimov et al., 2006, 2011). The GA core is clamped by canonical base pairs which are mostly $G=C$ standard WC. The following $5^{\prime}$ domain mutations were introduced into full-length BC1 RNA. B, The WC mutation abolishes the 5' BC1 GA motif by conversion to WC base pairing. $C$, Mutant 5 ' BC1 $\Delta \mathrm{U} 22$ lacks the unpaired $\mathrm{U}$ residue at position 22. $D$, In mutant $5^{\prime} \mathrm{BC} 1 \triangle \mathrm{IL}$, the basal internal loop has been eliminated by conversion to WC base pairing. Substitution mutations are indicated in red.

Scientific) according to the manufacturer's instructions. Then, $200 \mathrm{~nm}$ primers, $500 \mathrm{ng}$ of plasmid pBC200 and $1 \mu \mathrm{l}$ of dCTP $(3000 \mathrm{ci} / \mathrm{mmol}$, PerkinElmer) were added to $45 \mu \mathrm{l}$ of master mix. PCR amplification conditions were as follows: 1 cycle of $1.5 \mathrm{~min}$ at $94^{\circ} \mathrm{C}, 45 \mathrm{~s}$ at $56^{\circ} \mathrm{C}, 1 \mathrm{~min}$ at $72^{\circ} \mathrm{C}$, followed by 39 cycles of $30 \mathrm{~s}$ at $94^{\circ} \mathrm{C}, 45 \mathrm{~s}$ at $57^{\circ} \mathrm{C}, 1 \mathrm{~min}$ at $72^{\circ} \mathrm{C}$, and a final cycle of $1 \mathrm{~min}$ at $94^{\circ} \mathrm{C}, 45 \mathrm{~s}$ at $57^{\circ} \mathrm{C}, 15 \mathrm{~min} 72^{\circ} \mathrm{C}$. PCR products were run on a $2 \%$ agarose gel and purified from the gel using QIAquick gel extraction kits (Qiagen).

RNA expression constructs. Transcripts were generated from the following BC RNA plasmid constructs: (1) pBCX607 to generate full-length rat BC1 RNA (Muslimov et al., 2006, 2011), (2) pUC57_BC200 to generate full-length human BC200 RNA (Muslimov et al., 2018), (3) pBC1 $1_{\text {IL-A:WC }}$ to generate BC1 RNA with the GA apical internal loop motif replaced with standard Wilson-Crick (WC) base pairs (Muslimov et al., 2006), (4) $\mathrm{pBC1}_{\triangle \mathrm{U} 22}$ to generate BC1 RNA lacking U22 (Muslimov et al., 2006), (5) $\mathrm{pBC} 1_{\mathrm{IL}-\mathrm{B}: W C}$ to generate BC1 RNA with the basal internal loop replaced with a standard WC base pair by a C61A transversion (Muslimov et al., 2006), (6) pBC200 to generate the $5^{\prime}$ domain of BC200 RNA (Muddashetty et al., 2002), and (7) pVL450-1 to generate the 3' domain of BC200 RNA (Tiedge et al., 1993). U4 and U6 RNAs were generated from plasmids pSP6-U4 and pSP6-U6, respectively (Tiedge et al., 1991; Muslimov et al., 1997; Wang et al., 2005). All constructs were verified by sequencing.

Plasmids were linearized, and ${ }^{35} \mathrm{~S}$ - or ${ }^{32} \mathrm{P}$-labeled transcripts were generated using T3, T7 RNA, or SP6 polymerase as described previously (Muslimov et al., 2004, 2006; Wang et al., 2005; and references cited in the preceding paragraph). Excess unlabeled UTP was added to reactions to ensure that labeled transcripts were full-length, and size, integrity, and stability of all transcripts were monitored as described previously (Musli- mov et al., 1997, 2006, 2011). The secondary structures of WT and mutant $5^{\prime} \mathrm{BC} 1$ domains that were used in this work are shown in Figure 1 (see also Muslimov et al., 2006).

Electrophoretic mobility shift assay (EMSA). RNAs were ${ }^{32} \mathrm{P}$-labeled at $50,000 \mathrm{cpm}$ per reaction $(\sim 10 \mathrm{ng})$. RNAs were preheated at $70^{\circ} \mathrm{C}$ for 10 $\mathrm{min}$, allowed to cool for $5 \mathrm{~min}$ at room temperature, and incubated with antibodies using $1 \mu \mathrm{l}$ of serum or purified IgG preparation (elution 1 ; see above, antibody purification) in a total of $20 \mu \mathrm{l}$ of binding buffer (100 mм KCl, 3 mм $\mathrm{MgCl}_{2}, 2$ mм DTT, 5\% glycerol, and $20 \mathrm{~mm}$ HEPES, pH 7.6) for $30 \mathrm{~min}$ at $37^{\circ} \mathrm{C}$. Heparin was added at $5 \mathrm{mg} / \mathrm{ml}$ and incubated for $10 \mathrm{~min}$ at room temperature to minimize unspecific RNA-protein interactions. When desired, unbound RNA was digested using RNase T1 at $30^{\circ} \mathrm{C}$ for $10 \mathrm{~min}$. RNA-antibody complexes were resolved by $5 \%$ PAGE (TBE precast gels, Bio-Rad) in Tris/borate/EDTA (TBE) running buffer (prerun for $1 \mathrm{~h}$ at $30 \mathrm{~mA}$, run for $2 \mathrm{~h}$ at $25 \mathrm{~mA}$ ) and visualized by autoradiography.

EMSA competition experiments (competition between IgGs and hnRNP A2) were performed as follows (Muslimov et al., 2018). Recombinant full-length hnRNP A2 was expressed (Muslimov et al., 2011, 2014, 2018) from plasmid pET-9c (Munro et al., 1999). Purified hnRNP A2 (10 $\mathrm{nM}$ ) was preincubated with radiolabeled $\mathrm{BC} 1$ or $\mathrm{BC} 200 \mathrm{RNA}$, or derivatives, in $10 \mu \mathrm{l}$ of binding buffer at $37^{\circ} \mathrm{C}$ for $30 \mathrm{~min}$. IgG was added $(1: 1$ molar ratio IgG to hnRNP A2), and incubation was continued for another $30 \mathrm{~min}$, or longer as detailed in the figures. RNA-antibody complexes were resolved on $8 \%$ polyacrylamide gels (ratio acrylamide/ bisacrylamide 19:1) in $90 \mathrm{~mm}$ Tris-borate, $\mathrm{pH} 8.3,15 \mathrm{mM} \mathrm{MgCl}_{2}$, at room temperature for $12 \mathrm{~h}$ at $15 \mathrm{~V}$ (Muslimov et al., 2018).

EMSA results were quantified as follows. Dried gels were exposed to autoradiographic film; films were scanned, and bands representing im- 
mune complexes were analyzed using ImageJ (NIH). Signal intensities were recorded in relative signal intensity units (SIUs). Signal intensities of $<500$ SIUs were considered background level (i.e., absence of signal) and classified as no reactivity. Signal intensities of 500-20,000 SIU were classified as low reactivity. Signal intensities of $>20,000$ SIU were classified as high reactivity.

Cell culture. Sympathetic neurons were maintained in low-density primary cultures (Muslimov et al., 2006, 2011, 2014). Neurons were prepared from superior cervical ganglia isolated from E19-E20 Sprague Dawley rat embryos (of either sex) and grown on glass coverslips precoated with $100 \mu \mathrm{g} / \mathrm{ml}$ filter-sterilized poly-D-lysine (Sigma-Aldrich). Composition of culture media was as follows: $50 \%(\mathrm{v} / \mathrm{v})$ of Ham's F12 and DMEM (Life Technologies), BSA (500 $\mu \mathrm{g} / \mathrm{ml}$; Calbiochem), bovine insulin $(10 \mu \mathrm{g} / \mathrm{ml}$; Sigma-Aldrich), rat transferrin $(20 \mu \mathrm{g} / \mathrm{ml}$; Jackson ImmunoResearch Laboratories), L-glutamine ( $20 \mu \mathrm{g} / \mathrm{ml}$; Life Technologies), sodium selenite ( $5 \mathrm{ng} / \mathrm{ml}$; Sigma-Aldrich), and nerve growth factor ( $\beta$-NGF, $100 \mathrm{ng} / \mathrm{ml}$; Harlan Bioproducts for Science). Dendritic growth was induced by addition of basement membrane extract (Matrigel, 100 $\mu \mathrm{g} / \mathrm{ml}$; Collaborative Biomedical Products) on the third day in vitro. Cytosine arabinofuranoside (Ara-C, $2 \mu \mathrm{M}$; Sigma-Aldrich) was added on the second and fifth days after plating to minimize proliferation of nonneuronal cells. Work with vertebrate animals was approved by the SUNY DMC Institutional Animal Care and Use Committee.

Cultured sympathetic neurons were microinjected with RNA (Muslimov et al., 2004, 2006, 2011, 2014) as follows. RNAs were ${ }^{35} \mathrm{~S}$ radiolabeled at $3 \times 10^{6} \mathrm{cpm} / \mu$ l. Perikaryal injection was performed at volumes of a few femtoliters per pulse. Lucifer yellow (LY, $0.4 \%$ ) was coinjected to monitor the injection process and to ascertain that experimental manipulations did not cause alterations in cell morphology, including dendritic extent and arborization, over the course of the experiments (Muslimov et al., 2006, 2014). Transcript stability was ascertained preinjection by PAGE, postinjection by measuring average integrated total signal intensities per injected cell (Muslimov et al., 2006, 2011, 2014), and by incubation with brain extract (Muslimov et al., 2011, 2014).

We have opted for microinjection of radiolabeled transcripts to introduce RNAs into cells. The reason for this preference is twofold (Muslimov et al., 2014). In our experience, microinjection affords exquisite control of amounts of RNA introduced. Therefore, in combination with the high sensitivity of radiolabel detection, microinjection allows us to maintain the number of introduced RNA molecules at levels lower than those of respective endogenous RNA molecules (Muslimov et al., 2006, 2014). We remain committed to using radiolabeled RNAs because architectural GA motifs, central to dendritic targeting of BC RNAs, are quite intolerant of nucleotide substitutions and of introduced side chains (such as fluorophores) as they may disrupt motif structure and, as a result, interfere with targeting (Goody et al., 2004; Muslimov et al., 2011, 2014).

For coinjection experiments, radiolabeled $\mathrm{BC} 1$ or BC200 RNAs were incubated with purified IgG preparations for $30 \mathrm{~min}$ in $\mathrm{PBS}$ at $37^{\circ} \mathrm{C}$ before microinjection. In bath application experiments, purified IgG preparations were added to culture media at a dilution of 1:100 and incubated for various periods of time before microinjection of BC1 RNA or BC200 RNA. IgG bath incubation time ranged from $1 \mathrm{~h}$ to overnight. The full effect of bath-applied IgGs (e.g., diminished dendritic targeting after application of IgG SLE S1 or S6) was observed after incubation periods of $8 \mathrm{~h}$ or more. In the experiments presented in the Results section, $8 \mathrm{~h}$ incubation periods were chosen for bath-applied IgGs.

Injection of mice with sera and antibodies. We adhered to the protocol of the Diamond laboratory (Kowal et al., 2006) for this approach. Male $\mathrm{BALB} / \mathrm{c}$ mice (age 6-8 weeks; Jackson Laboratory) were injected intravenously with SLE or non-SLE sera or purified IgG fractions. The retroorbital route (Schoch et al., 2014) was used for intravenous injections. Sera were injected on day 1 (100 $\mu \mathrm{l}$, right side) and on day $2(100 \mu \mathrm{l}$, left side). Intravenous injections of purified IgG fractions $(0.5 \mathrm{mg} / \mathrm{ml}$ in 100 $\mu \mathrm{l}$ of saline) were performed analogously. $15 \mathrm{~min}$ after each serum or IgG injection, lipopolysaccharide (LPS, $3 \mathrm{mg} / \mathrm{kg}$ ) was injected intraperitoneally. LPS intraperitoneal injections were repeated $2 \mathrm{~d}$ after the last intravenous injection. Animals were killed $2 \mathrm{~d}$ later. We anticipated that this time frame would be sufficiently long to allow for clearance of preexisting endogenous BC1 RNA from dendrites (Muslimov et al., 2011) but not long enough to risk clearance of injected antibodies from circulation and brain (Schoch et al., 2014).

Animals were intravenously injected with sera or purified IgG fractions as follows: IgG SLE S1, 8 animals; serum SLE S1, 2 animals; serum SLE S6, 2 animals; IgG HS4, 4 animals; serum HS4, 4 animals; IgG RA1, 1 animal; IgG MS1, 1 animal. BC1 RNA localization data from IgG SLE S1, serum SLE S1, and serum SLE S6 injected animals did not qualitatively or quantitatively differ from each other and were therefore combined for analysis (total number of animals: 12). Analogously, BC1 RNA localization data from IgG HS4, serum HS4, IgG RA1, and IgG MS1 injected animals did not qualitatively or quantitatively differ from each other and were therefore combined for analysis (total number of animals: 10).

In situ hybridization. We performed in situ hybridization to examine BC1 RNA dendritic localization deficits in vivo. Animals that had been injected with SLE anti-BC sera or abs, and animals that had been injected with non-SLE sera or abs, were perfusion fixed, their brains prepared, cryosectioned at $10 \mu \mathrm{m}$ thickness (coronal sections were generated), and hybridized with anti-BC1 RNA probes (or "sense"-strand control probes) as described previously (Tiedge et al., 1991; Tiedge, 1991; Lin et al., 2001). We continue to prefer ${ }^{35}$ S-labeled probes (Tiedge et al., 1991; Lin et al., 2001; Muslimov et al., 2018) as we find that nonradioactively labeled BC1 RNA probes are prone to generating unspecific labeling artifacts. After extensive high-stringency washes, sections were dried and exposed to autoradiographic film and subsequently to autoradiographic emulsion (Lin et al., 2001). Sections were counterstained with cresyl violet (Lin et al., 2001).

Microscopy. Photomicrographs [dark field, phase contrast, and differential interference contrast (DIC Nomarski)] were taken on a Nikon Microphot-FXA microscope with a Digital Sight DS-Fil 5-megapixel charge-coupled device (CCD) camera (Eom et al., 2014; Muslimov et al., 2018). The following objectives were used: (1) Plan Fluor $10 \times / 0.30$, 160/0.17; (2) Ph2 Plan 20×/0.50, DL 160/0.17; (3) Ph3 DL Plan 40×/ 0.65, 160/0.17; Plan 20/0.70 DIC 160/0.17. Illustrations were generated using Photoshop and final figures were arranged in Illustrator (both Adobe Systems).

Experimental design and statistical analysis. For dendritic transport experiments using sympathetic neurons in primary culture, the experimental design followed a previously published protocol (Muslimov et al., $1997,2004,2006,2011,2014)$. Each RNA was injected at a range of concentrations (covering at least one order of magnitude) to ensure that observed dendritic targeting patterns were independent of amounts injected. The number of neurons and dendrites analyzed is given for each experiment. Dendritic localization of injected RNAs was quantified as follows. Silver grain densities were measured along dendritic extents at 50 $\mu \mathrm{m}$ interval points, up to a length of $250 \mu \mathrm{m}$. A relative signal of $100 \%$ was assigned to levels at the base of dendrites ( $0 \mu \mathrm{m}$ points). Statistical significance was examined using one-way ANOVA followed by Dunnett's multiple-comparisons analysis in which dendritic RNA levels were compared at all interval points (Muslimov et al., 1997, 2004, 2006, 2011, 2014). Herein, data points and error bars are given as mean \pm SEM.

For in vivo BC1 RNA localization experiments, ${ }^{35}$ S-labeled RNA probes were used as described above (Lin et al., 2001). Quantification and statistical analysis were performed as follows. Silver grain densities were obtained as a measure of relative labeling signal (Muslimov et al., 2004, 2018). Signal intensities were established from hybridized cryosections of hippocampal CA1 in stratum pyramidale (center), in stratum oriens at a distance of $50 \mu \mathrm{m}$ from the edge of stratum pyramidale, and in stratum radiatum at distances of 50,100, and $150 \mu \mathrm{m}$ from the edge of stratum pyramidale, Statistical significance was examined using one-way ANOVA followed by Tukey's or Dunnett's multiple-comparisons analysis, comparing signal intensities in strata pyramidale, oriens, and radiatum at sample points defined above (Muslimov et al., 2018).

Nonparametric Spearman's rank-order correlation analysis was performed as described previously (Mus et al., 2007). The Spearman's approach was used to examine a correlation of SLE with or without neuropsychiatric manifestations (seizures, OBS) on one hand with the strength of anti-BC autoimmune reactivity on the other. Results were 
A

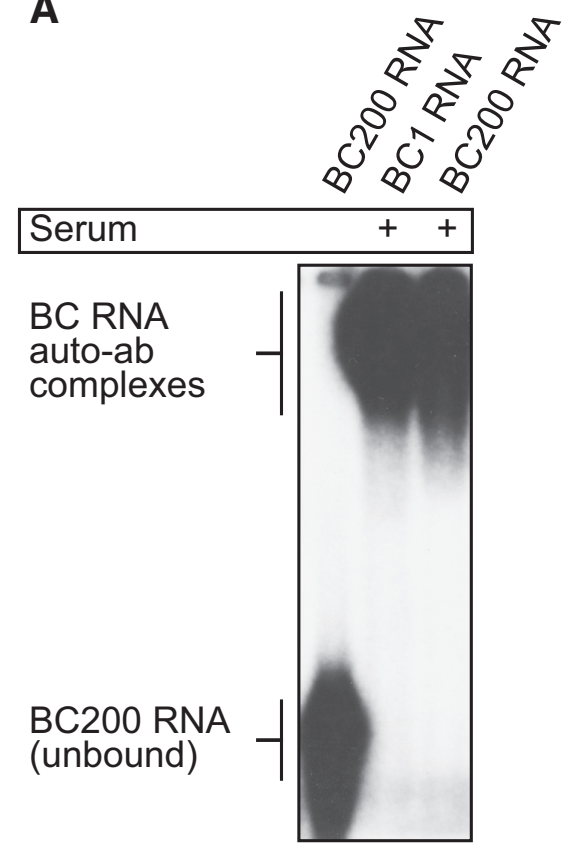

C

Fractions $\quad S \quad F T$ El1 El2 El3

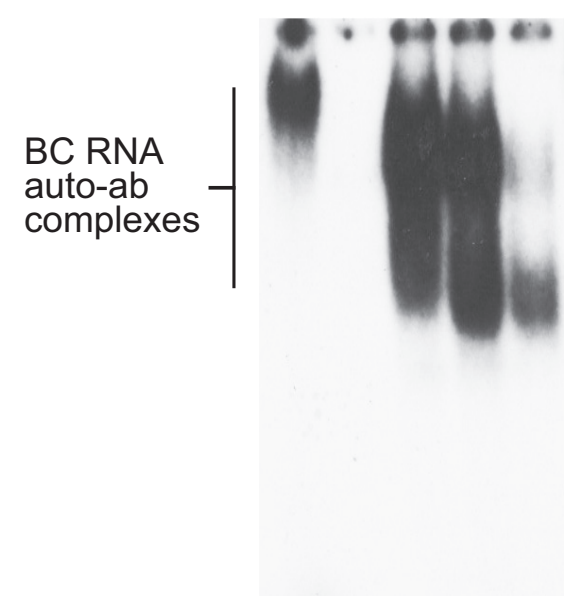

B

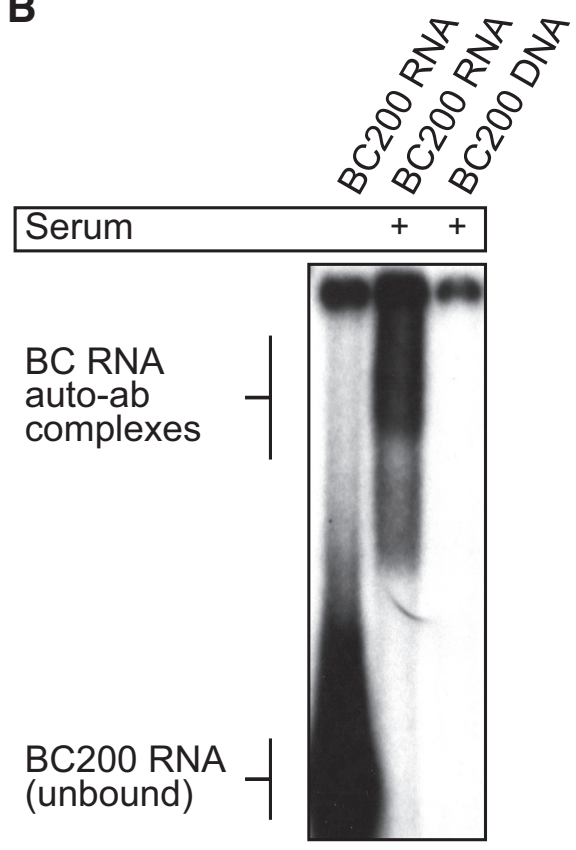

Figure 2. SLE autoimmune responses to BC RNAs. $A,{ }^{32}$ P-labeled $B C 1$ and BC200 RNAs were used in In EMSA analysis. RNAs bound in immune complexes were resolved from unbound RNAs by PAGE. BC1 and BC200 RNAs formed complexes with serum components from an SLE patient. $B$, The same serum was found nonreactive to BC200 DNA. Serum used in the experiments shown here was from SLE patient S1 (see below for patient codes). C, After antibody purification from serum (S) using Protein G, flow-through (FT) and three stepwise elution fractions (El1, El2, El3) were tested for anti-BC RNA reactivity by EMSA. While no reactivity was detected in FT, strong reactivity was apparent in E1 and E2 and weak reactivity was observed in E3. In this and the following figures, SLE autoantibodies are identified by patient codes in which a number may be preceded by the letters S (indicating an SLE patient with a history of seizures) or OBS (indicating an SLE patient with organic brain syndrome). SLE patients with no history of seizures or OBS are identified by numbers without preceding letters. See also Materials and Methods.

expressed in the form of a Spearman's rank correlation coefficient (Spearman's $\rho$ or $\mathrm{r}_{\mathrm{S}}$ ). The Mann-Whitney $U$ test was used to compare the distribution of anti-BC autoimmune reactivity in SLE versus non-SLE samples.

Quantitative and statistical analysis was performed using Prism (GraphPad) and SPSS Statistics (IBM, RRID:SCR_002865) software.

\section{Results}

\section{Screening of sera}

To begin to test the hypothesis of anti-BC RNA autoimmune responses in SLE, we screened sera from a total of 107 subjects, including 69 SLE patients, for autoantibodies directed against human BC200 RNA. Subjects were categorized as belonging to one of seven groups as listed in Table 1. Subjects had been diagnosed as follows: SLE with seizures (Group I), SLE with organic brain syndrome (Group II), SLE (Group III), HS (Group IV), RA (Group V), UC (Group VI), and MS (Group VII).

Our screen revealed that of 69 SLE patient sera (Groups I-III), 54 tested positive for antibodies against BC RNAs, 18 of them with high reactivity (Table 1). Electrophoretic mobility shift assay (EMSA) analysis indicated that positive SLE sera were reactive to human BC200 RNA and rat BC1 RNA as they formed lowermobility immune complexes with both RNAs (Fig. 2A).

Select SLE autoantibodies have been reported to bind doublestranded DNA (dsDNA) (Uccellini et al., 2012; Mader et al., 
A
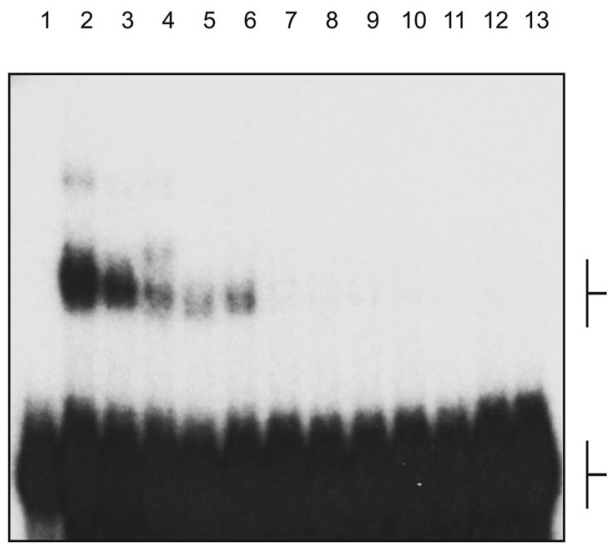

C

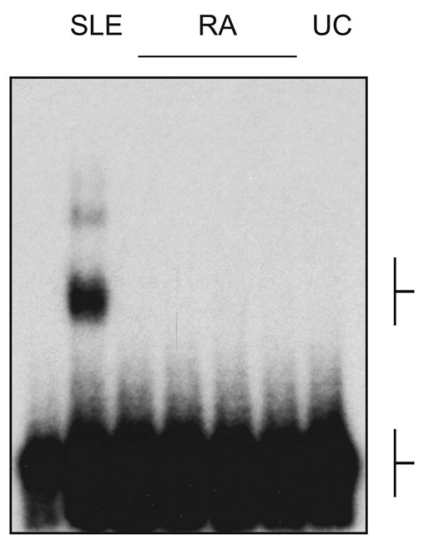
Auto-ab
B

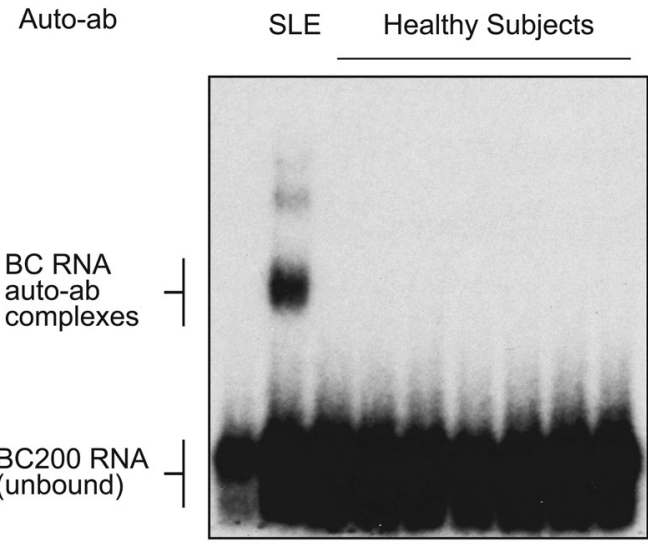

D SLE MS

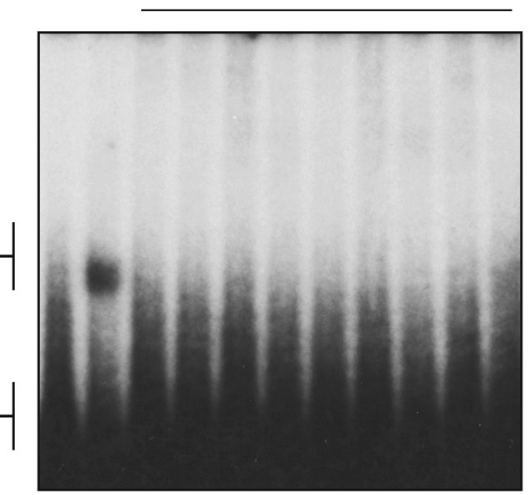

Figure 3. Anti-BC RNA reactivity of purified lgG preparations from sera of SLE patients, HS, and patients with non-SLE autoimmune diseases. ${ }^{32}$ P-labeled BC200 RNA was used for EMSA analysis. $B C 200$ RNA in autoantibody-RNA complexes was separated from unbound BC200 RNA by PAGE. RNA only was loaded in the left-most lane of each of the four gels shown in $\boldsymbol{A}-\boldsymbol{D}$. Preincubated RNA - antibody reaction mixtures were loaded in subsequent lanes of the gels $\boldsymbol{A}-\boldsymbol{D}$. $\boldsymbol{A}, \mathrm{BC} 200 \mathrm{RNA}$ was preincubated with $\mathrm{g} G$ preparations from SLE patients. Anti-BC $200 \mathrm{RNA}$ autoimmune reactivity was found varying among SLE IgG preparations between strong (lane 2 and 3 , patients $S 1$ and $S 6$, respectively), weak (lanes $4-6$, patients $S 13, S 20$, and $0 B S 16$, respectively), and nondetectable (lanes $7-13$, patients $3,15, S 26,0 B S 18,10, S 16$, and OBS15, respectively). Anti-BC 200 RNA reactivity was not detected in lgG preparations from subjects with no evidence of disease (HS, $B$, or in lgG preparations from patients with autoimmune diseases other than SLE, including RA (C), UC ( $(\boldsymbol{C})$, or MS (D). For a positive reference (i.e., demonstration of autoantibody-RNA complexes) in gels $\boldsymbol{B}-\boldsymbol{D}$, reaction mixtures of BC200 RNA preincubated with IgG SLES1 were loaded in respective lanes 2. SLE autoantibody-BC RNA immune complexes often occur at two distinct electrophoretic mobilities: a strong band running at higher mobility (indicated as BC RNA auto-ab complexes), likely representing immune complexes containing one ab binding one RNA molecule, and a weaker band running at lower mobility, likely representing immune complexes containing one ab binding two RNA molecules. Electrophoretic mobility of BC RNA auto-ab complexes was lower with sera from SLE patients (Fig. 2) than with IgG preparations that were affinity-purified from such sera (this figure). It is possible that serum components interacting with immune complexes (Junghans and Anderson, 1996; Qiao et al., 2008; Suzuki et al., 2010; e.g., FcRn) are responsible for this additional shift to lower mobility.

2017). We therefore asked whether SLE anti-BC sera would also recognize genomic BC200 DNA. Results in Figure $2 B$ show that this is not the case as BC200 dsDNA, in contrast to BC200 RNA, was not mobility-shifted. The data indicate that SLE anti-BC abs reactivity is specifically RNA-directed.

We subsequently affinity-purified antibodies from the 18 high-reactivity SLE sera (using protein A/G and protein G Sepharose columns; see Materials and Methods) and determined that, in each case, anti-BC reactivity was associated with the IgG class of immunoglobulins (Fig. 2C). These antibodies will In the following be referred to as anti-BC IgGs.

Among the SLE IgG samples tested, reactivity to BC200 RNA ranged from strong (Fig. $3 A$, lanes 2 and 3 ) to weak (Fig. $3 A$, lanes 4-6) to undetectable (Fig. $3 A$, lanes 7-13). Strong anti-BC RNA immune reactivity was detected in $36 \%$ of SLE cases with a history of seizures (Table 1, Group I), in 18\% of SLE cases with organic brain syndrome (OBS; Table 1, Group II), and in $21 \%$ of cases without neurological symptoms (Table 1, Group III). Non- parametric Spearman's rank-order correlation analysis revealed a strong correlation between the strength of SLE anti-BC autoimmune reactivity and the occurrence of neuropsychiatric manifestations (Spearman's correlation coefficient $r_{s}=0.89,95 \%$ confidence interval 0.83-0.93, $p<0.0001, n=69$ ).

By contrast, anti-BC RNA immune reactivity was not detected with IgGs from HS without evidence of disease (Fig. 3B; Table 1, Group IV) or with IgGs from patients with autoimmune diseases other than SLE (Table 1, Groups V-VII). Specifically, no anti-BC RNA immune reactivity was found with IgGs from patients with RA (Fig. 3C), UC (Fig. 3C), or MS (Fig. 3D). We conclude that the observed anti-BC RNA autoimmune responses are specific for SLE and are not triggered in patients with other systemic (RA, MS) or localized (UC) autoimmune diseases, or in HS (Mann-Whitney $U$ test, comparison of anti-BC autoimmune reactivity levels between SLE and non-SLE samples, $p<0.0001, n=69$ ). 
A
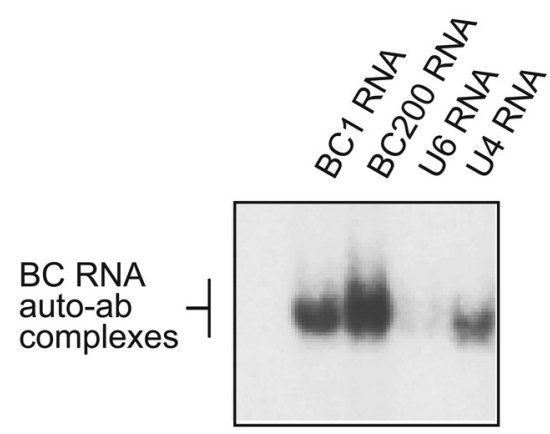

C

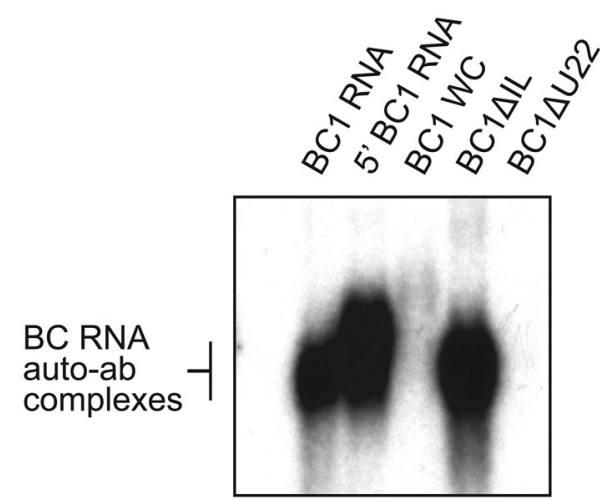

B

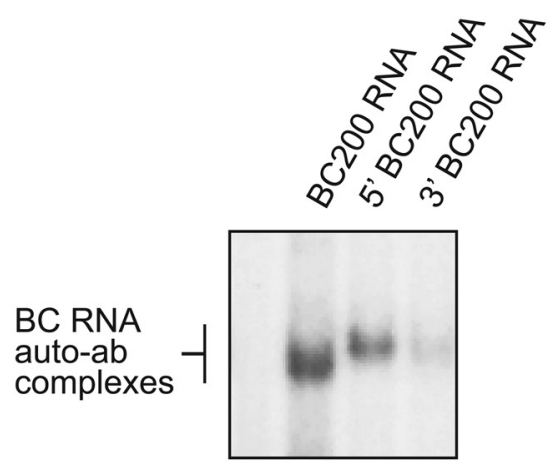

Figure 4. Molecular targets of SLE anti-BC autoimmune reactivity. EMSA experiments were performed with ${ }^{32}$ P-labeled human BC200 RNA and rat BC1 RNA, using purified IgGs from SLE patient S6. $A$, Strong immune complex formation of IgG SLE S6 was apparent with BC200 RNA and BC1 RNA, with stronger reactivity toward the human than to the rat BC RNA. Immune complex formation was weak with spliceosomal U4 snRNA and undetectable with spliceosomal U6 snRNA. $B$, Robust reactivity was observed against full-length BC200 RNA and against the $5^{\prime}$ BC200 domain, but not against the $3^{\prime}$ BC200 domain. C, IgG SLE S6 formed immune complexes with full-length BC1 RNA and with its 5' BC1 domain. When the 5' DTE-resident GA motif was altered to standard A-form RNA helix by conversion of noncanonical base-pairings to standard WC base pairings (BC1 WC, see Fig. 1 for structure), full-length BC1 RNA was no longer recognized by lgG SLE S6. Similarly, IgG SLE S6 did not recognize full-length BC1 RNA in which $5^{\prime}$ DTE unpaired $U 22$ had been deleted (BC1 $\triangle U 22$ ). By contrast, elimination of the $5^{\prime}$ basal internal loop (BC1 $\triangle I L$ ) did not perceptibly alter BC1 RNA recognition by anti-BC IgG SLE S6. In each of the gels $A-C$, RNA only was loaded in the left-most lane, and no complex formation was observed. While lgG SLE S6 was used in experiments shown in this figure, analogous results were obtained with three other lgG preparations purified from highly reactive SLE sera (Table 1).

\section{Molecular-structural targets of SLE anti-BC abs}

BC RNA functionality is physically compartmentalized along structural domains and resident architectural motifs (Iacoangeli and Tiedge, 2013; Eom et al., 2018). To be able to appreciate the functional implications of SLE anti-BC RNA autoimmune reactivity, it was therefore important to identify the molecular epitope target(s) of anti-BC abs. Rodent BC1 RNA and primate BC200 RNA are organized into tripartite structures in which a 5' stem-loop domain is linked to a $3^{\prime}$ stem-loop domain by a single-stranded A-rich central domain (DeChiara and Brosius, 1987; Tiedge et al., 1993; Skryabin et al., 1998; Rozhdestvensky et al., 2001; Iacoangeli and Tiedge, 2013). While the BC1 and BC200 3 ' stem-loop structures mediate translational control (Lin et al., 2008; Eom et al., 2011, 2014, 2018), the 5' stem-loops carry spatial codes that, acting as DTEs, specify RNA delivery to synaptodendritic sites of function (Muslimov et al., 1997, 2006, 2011).

To address the question which BC RNA epitopes are targeted by anti-BC abs, we performed EMSA analysis with purified SLE IgG preparations to examine interactions with human BC200 $\mathrm{RNA}$, rat BC1 RNA, and respective subdomains or mutants. We found that SLE anti-BC RNA reactivity (using IgG SLE S6, i.e., purified IgG from an SLE patient with a history of seizures \#6) was directed at both human BC200 RNA and rat BC1 RNA (Fig. $4 A$ ), confirming the results obtained with sera (Fig. 2). Anti-BC reactivity was stronger toward human $\mathrm{BC} 200$ RNA than to rat BC1 RNA (Fig. 4A). Limited crossreactivity of IgG SLE S6 was observed with small nuclear (sn) U4 RNA but not with U6
snRNA (Fig. 4A). U4 and U6 RNAs are spliceosome components; it is noted that U4 RNA (Vidovic et al., 2000; Klein et al., 2001), but not U6 RNA (Karaduman et al., 2006), contains a noncanonical GA motif which, although different from BC RNA GA motifs described below, may be underlying the observed crossreactivity. For IgG SLE S6, crossreactivity with U4 RNA was estimated at $<5 \%$ of the reactivity level with BC200 RNA (Fig. $4 A$ ). Finally, we found that SLE IgG anti-BC reactivity was directed at the $5^{\prime}$ stemloop domain as the $3^{\prime}$ domain was poorly recognized (Fig. $4 B$ ).

In double-stranded RNA domains, it is frequently architectural motifs rather than sequence content that serve as recognition codes for RNA binding proteins (Noller, 2005; Leontis et al., 2006). The 5' domains of BC1 RNA and BC200 RNA contain several such motifs (Skryabin et al., 1998; Muslimov et al., 2006, 2011, 2018; Iacoangeli and Tiedge, 2013; Eom et al., 2018) which for BC1 RNA include an apical noncanonical GA motif, an unpaired U-residue at position 22 (U22), and a basal internal loop (Fig. 1). The BC1 GA motif features noncanonical (i.e., non-WC) purine•purine interactions in which tandem $G \cdot A / A \cdot G$ pairs engage in Hoogsteen-type hydrogen bonding (Muslimov et al., 2006, 2011; Iacoangeli and Tiedge, 2013; Eom et al., 2018) (Fig. 1).

We investigated whether any of the three BC1 RNA 5' architectural motifs are recognized as antigenic epitopes by SLE anti-BC abs. SLE anti-BC IgGs were used with WT BC1 RNA and with BC1 RNA derivatives in which one of these motifs had been altered by point mutations (see Fig. 1 for structures of the mu- 
tants used). We found that in BC1 RNA, the $5^{\prime}$ domain noncanonical GA motif and unpaired U22 were both indispensable for SLE autoantibody recognition (Fig. 4C). The 5 ' domain basal internal loop, in contrast, was recognition irrelevant (Fig. 4C).

A requirement of the noncanonical GA motif and unpaired $\mathrm{U} 22$ for SLE anti-BC ab recognition is remarkable as it is precisely these structural attributes in the 5' $\mathrm{BC} 1$ domain that have previously been identified as instrumental in specifying dendritic targeting competence (Muslimov et al., 2006, 2011; Eom et al., 2018). Thus, the noncanonical GA motif and unpaired U22 are resident and requisite structural components of the 5' BC1 DTE, and both motifs (but not the basal internal loop) are indispensable for dendritic delivery (Muslimov et al., 2006, 2011). The above data thus indicate that SLE anti-BC abs interact with exactly those $5^{\prime} \mathrm{BC} 1$ DTE architectural attributes that are responsible for dendritic targeting.

\section{Molecular competition of SLE anti-BC abs with RNA transport factor hnRNP A2 for access to BC RNAs}

The results presented in the preceding section indicate that SLE anti-BC abs can target RNA structural epitopes that serve as DTE spatial codes for BC RNA synapto-dendritic delivery. Subcellular transport of $\mathrm{BC} 1$ and $\mathrm{BC} 200$ RNAs is mediated by the RNA transport factor hnRNP A2 via interactions with 5' DTEs (Muslimov et al., 2006, 2011; Iacoangeli and Tiedge, 2013; Eom et al., 2018). The question is thus raised whether SLE anti-BC abs compete with hnRNP A2 for binding to BC1 and BC200 RNAs.

To address this question, we performed EMSA analysis using purified IgGs from two SLE patient sera (IgG SLE S1 and IgG SLE S6). We first confirmed (Fig. 5A) that binding of IgG SLE S1 to both BC1 RNA and BC200 RNA was robust, whereas no binding was observed with IgGs from an HS(IgG HS4). Equally robust was binding of recombinant hnRNP A2 to BC1 RNA and BC200 RNA (Fig. 5A). Next, in an EMSA competition analysis, BC1 or BC200 RNA was preincubated with hnRNP A2. After $30 \mathrm{~min}$, IgG SLE S1 was added to the reaction mix, and incubation was continued for another $30 \mathrm{~min}$. At this time, hnRNP A2 was almost completely displaced from BC1 RNA and partially displaced from BC200 RNA (Fig. 5A). When incubation was extended to a total of $60 \mathrm{~min}$, hnRNP A2 was completely displaced from both RNAs (Fig. 5B). By contrast, no displacement from either RNA was observed with IgG HS4 (Fig. 5A).

BC RNA-anti-BC ab complex formation, and displacement of hnRNP A2, was analogously observed when IgG SLE S6 was used instead of IgG SLE S1 in EMSA competition analysis (Fig. 6A). Failure to form such complexes, in contrast, was apparent with IgG MS1 (MS patient) and with IgG RA1 (RA patient), in addition to IgG HS4 (Fig. 6B). The combined data indicate that binding of SLE anti-BC abs specifically and effectively prevents $\mathrm{BC} 1$ RNA and BC200 RNA from interacting with hnRNP A2.

Together, the evidence presented in this and the preceding section suggests that SLE anti-BC RNA autoimmune reactivity is primarily directed against targeting-relevant structural motifs in the 5' DTE domains, and that interaction of SLE anti-BC abs with such motifs displaces RNA transport factor hnRNP A2 from BC RNAs. These results invite the question of whether such competition will affect BC RNA dendritic delivery.

\section{SLE anti-BC abs: BC RNA dendritic transport impairments}

Does molecular displacement of hnRNP A2 by SLE anti-BC abs impact dendritic delivery of BC RNAs? We applied RNA transport assays using microinjection methodology with sympathetic neurons in primary culture (Muslimov et al., 1997, 2004, 2006, 2011,2014 ) to address this question. We microinjected perikaryal regions of cultured neurons with ${ }^{35} \mathrm{~S}$-radiolabeled full-length BC1 RNA or BC200 RNA. Progression of labeled RNAs into and along dendrites was monitored over various periods of time up to a total of $4 \mathrm{~h}$. In agreement with earlier data, BC1 RNA and BC200 RNA were transported to reach distal dendritic tips within the $4 \mathrm{~h}$ period (Muslimov et al., 1997, 2006, 2011).

In the next step, we preincubated radiolabeled BC1 RNA with purified IgGs from an HS (IgG HS4) for 30 min before coinjection into sympathetic neurons in primary culture. The resulting labeling signal extended along the entire dendritic extent (Fig. $7 A, B)$, indicating that IgG HS4 did not impact dendritic delivery of rodent $\mathrm{BC} 1 \mathrm{RNA}$. In clear contrast, $\mathrm{BC} 1 \mathrm{RNA}$ that had been preincubated and coinjected with IgG SLE S1 showed a somatically restricted distribution profile (Fig. $7 C, D$ ). The data indicate that SLE anti-BC abs were interfering with the transport of $\mathrm{BC} 1$ RNA along dendritic arborizations. By contrast again, when the same experiment was performed using IgG MS1 (i.e., autoimmune IgG from a MS patient), BC1 RNA was delivered normally to dendrites (Fig. $7 E, F$ ), and the somato-dendritic distribution pattern was not significantly different from that observed in the presence of coinjected IgG from an HS (Fig. 7G). For quantitative analysis (Fig. $7 G$ ), signal intensities were established along dendritic extents at $50 \mu \mathrm{m}$ interval points, up to a length of $250 \mu \mathrm{m}$. Statistical analysis was performed using one-way ANOVA followed by Dunnett's multiple-comparisons analysis [comparison of dendritic BC1 RNA levels after coinjection with IgG HS4 (Fig. $7 A, B$ ) with levels after coinjection with IgG SLE S1 (Fig. 7C,D), $p<0.0001$ for all interval points; comparison with levels after coinjection with IgG MS1 (Fig. $7 E, F$ ), $p>0.95$ for all interval points]. The data, together with those of Figure 5, support the hypothesis that SLE autoimmune abs (but not MS autoimmune abs), by displacing transport factor hnRNP A2, abolish or significantly reduce dendritic targeting of BC1 RNA.

Further experiments were performed for additional tests of the above hypothesis. As is detailed in the Introduction and Discussion sections, rodent BC1 RNA and primate BC200 RNA are not phylogenetic orthologs but appear to operate in neurons in a functionally-mechanistically analogous manner (Iacoangeli and Tiedge, 2013; Eom et al., 2018). To determine whether this functional analogy extends to dendritic targeting being susceptible to SLE anti-BC autoimmune reactivity, we performed RNA transport experiments with rodent BC1 RNA and primate BC200 RNA in parallel. As is shown in Figure 8, dendritic delivery of human BC200 RNA was significantly diminished after preincubation and coinjection of radiolabeled RNA with IgG SLE S1 (Fig. $8 C, D)$. By contrast, preincubation and coinjection with IgG HS4 (Fig. $8 A, B$ ) or IgG MS1 (Fig. $8 E, F$ ) did not result in reduced dendritic delivery of BC200 RNA (Fig. 8G). Quantitative analysis (Fig. 8G) was performed using one-way ANOVA followed by Dunnett's test [comparison of dendritic BC200 RNA levels after coinjection with IgG HS4 (Fig. 8A,B) with levels after coinjection with IgG SLE S1 (Fig. $8 C, D$ ), $p<0.0001$ for all interval points; comparison with levels after coinjection with IgG MS1 (Fig. $8 E, F), p>0.62$ for all interval points]. We conclude that dendritic targeting of rodent BC1 RNA (Fig. 7) and primate BC200 RNA (Fig. 8) is analogously inhibited by SLE IgGs but not by HS or MS patient IgGs.

Before being able to engage cytoplasmic regulatory BC RNAs, anti-BC abs will have to enter cells. Neurons have been shown to internalize IgGs, with uptake occurring via clathrin-dependent 


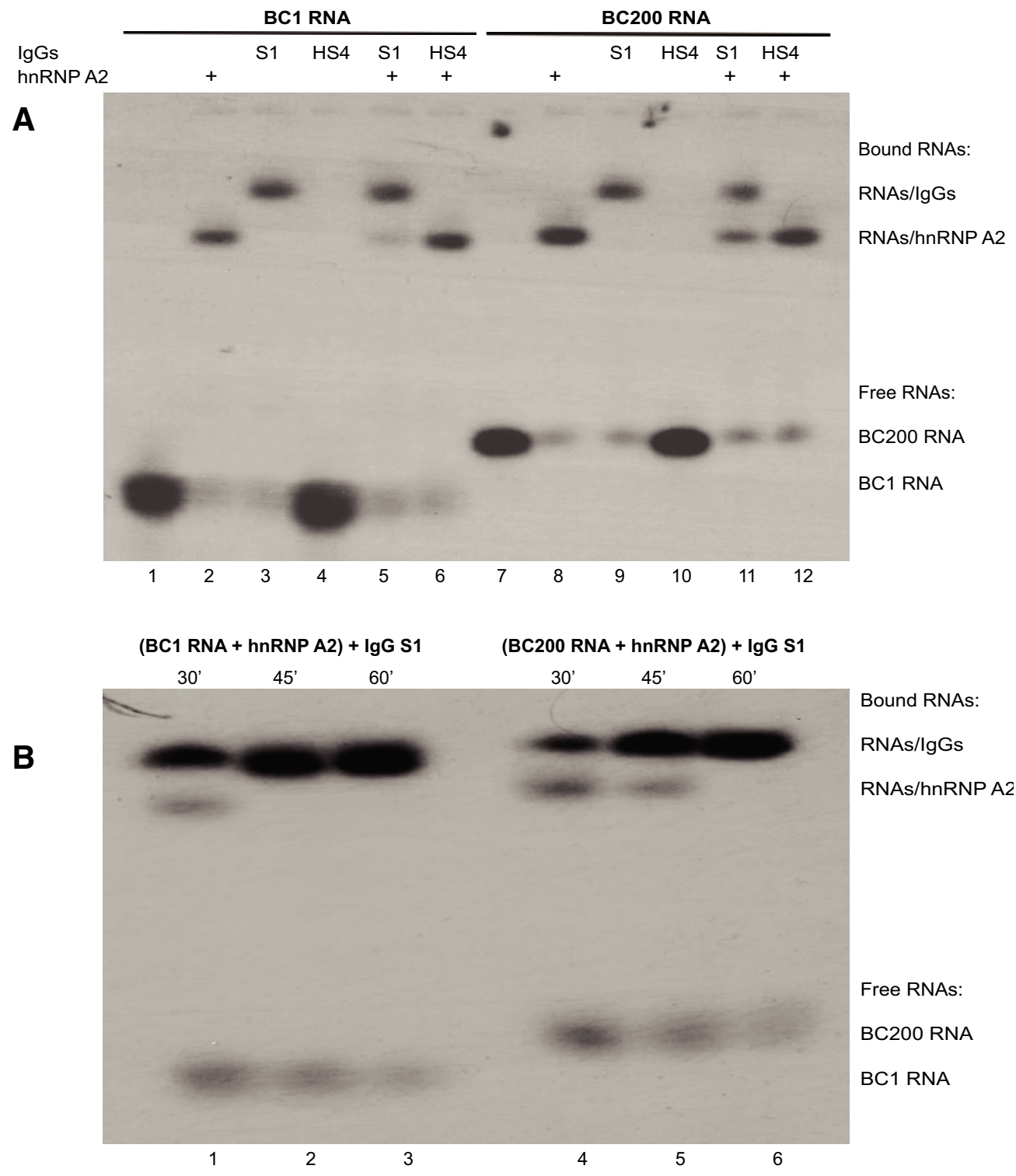

Figure 5. EMSA competition analysis: transport factor hnRNP $A 2$ is displaced from $B C 1$ and $B C 200$ RNAs by SLE anti-BC abs. $A$, ${ }^{32} P$-labeled $B C 1$ RNA was loaded in lanes $1-6$ as follows. Lane 1 , unbound BC1 RNA runs with high mobility. Lane 2, BC1 RNA incubated with hnRNP A2 runs at reduced mobility, reflecting BC1 RNA-hnRNP A2 complex formation. Lane 3, BC1 RNA incubated with IgG from SLE patient S1 runs at reduced mobility, reflecting BC1 RNA-anti-BC antibody immune complex formation. Lane 4, BC1 RNA incubated with lgG from HS4 runs at the same mobility as unbound BC1 RNA in lane 1, indicating lack of immune complex formation. Lane 5, BC1 RNA incubated with hnRNP A2 and, after 30 min, with lgG from SLE patient S1 runs with the same mobility as BC1 RNA incubated with lgG from SLE patient S1; thus, dual incubation produced mostly complexes containing BC1 RNA and lgG SLES1 rather than complexes containing BC1 RNA and hnRNP A2, indicating that hnRNP A2 had been displaced from BC1 RNA by IgG SLE S1. Lane 6, BC1 RNA incubated with hnRNP A2 and, after 30 min, with lgG from HS4 runs with the same mobility as BC1 RNA incubated with hnRNP A2; thus, dual incubation produced mostly complexes containing BC1 RNA and hnRNP A2 rather than complexes containing BC1 RNA and lgG HS4, indicating that IgG HS4 was unable to displace hnRNP A2 from BC1 RNA. Competition experiments with human BC200 RNA (lanes 7-12) were performed analogously. The molar ratio of IgG to hnRNP A2 was 1:1 in all cases. All final incubations were for $30 \mathrm{~min}$. Analogous results were obtained when lgG SLE S6 was used instead of IgG SLE S1 (Fig. 6A). Unbound BC200 RNA runs at lower mobility than BC1 RNA because the former is longer (200 nt) than the latter (152 nt). B, Time course experiments reveal displacement, by lgG SLES1, of hnRNP A2 from BC1 RNA (lanes 1-3) and from BC200 RNA (lanes 4 - 6). BC RNAs were incubated with hnRNP A2 and, after $30 \mathrm{~min}$, with IgG SLE S1. Incubation was continued for 30 min (lanes 1 and 4), 45 min (lanes 2 and 5), and 60 min (lanes 3 and 6). The data indicate that hnRNP A2 was completely displaced from BC1 RNA and BC200 RNA by lgG SLE S1 within 60 min.

Fc $\gamma$ receptor-mediated endocytosis (Elkon and Casali, 2008; Congdon et al., 2013; Douglas et al., 2013; Kazim et al., 2017; Rhodes and Isenberg, 2017). We reasoned that preincubation of cultured neurons with bath-applied SLE anti-BC IgGs would, after antibody uptake, cause BC RNA transport impairments identical or similar to those observed after antibody coinjection.

Two sets of experiments were performed to test this prediction. In the first set, we bath-applied IgGs to sympathetic neurons in culture for various periods of time (see Materials and Methods) before perikaryal microinjection of radiolabeled rat $\mathrm{BC} 1$
RNA. Data presented in Figure 9 show that an $8 \mathrm{~h}$ bath application of IgG SLE S6 (Fig. 9C,D), but not of IgG HS4 (Fig. 9A, $B$ ) or IgG RA1 (Fig. $9 E, F$ ), resulted in significantly reduced dendritic targeting of BC1 RNA (Fig. 9G). Quantitative analysis (Fig. 9G) was performed using one-way ANOVA followed by Dunnett's test [comparison of dendritic BC1 RNA levels after bath application of IgG HS4 (Fig. 9A,B) with levels after bath application of IgG SLE S6 (Fig. $9 C, D$ ), $p<0.0001$ for all interval points; comparison with levels after bath application of IgG RA1 (Fig. $9 E, F$ ), $p>0.73$ for all interval points]. 
A

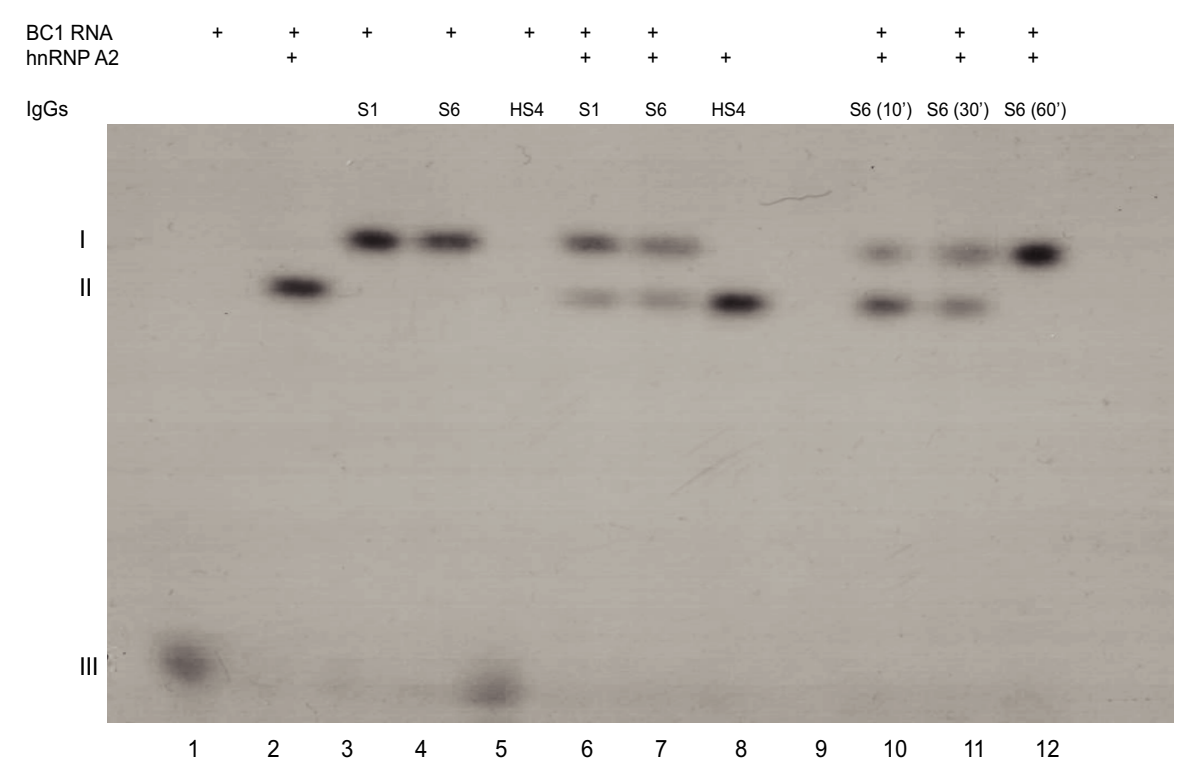

B

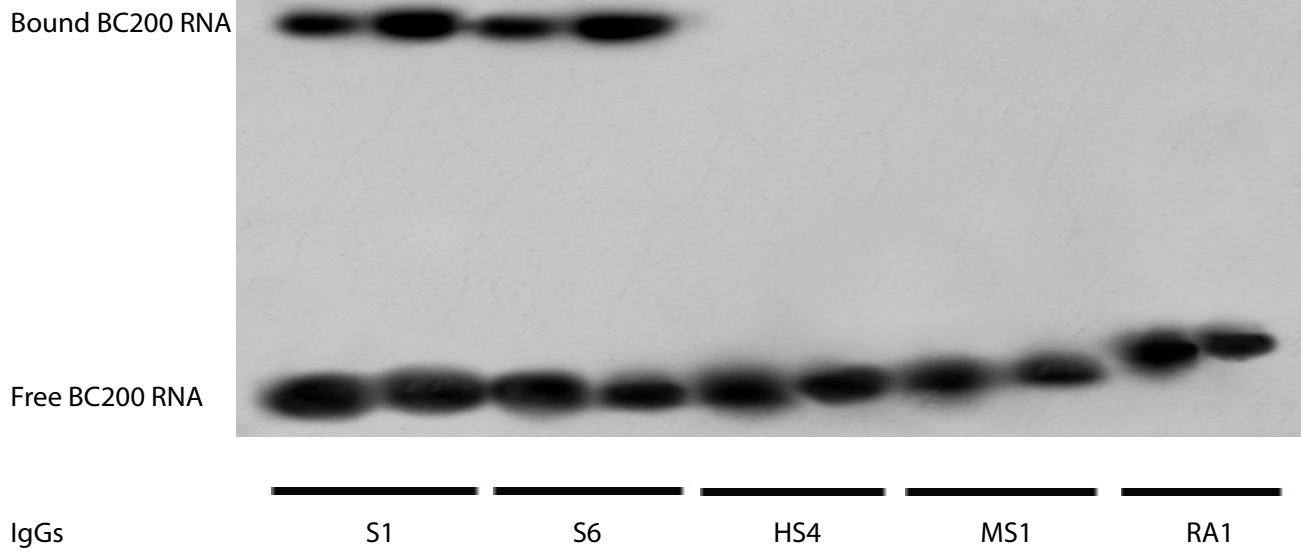

Figure 6. EMSA competition analysis: displacement of transport factor hnRNP A2 by anti-BC abs lgG SLES1 and lgG SLE S6. A, Displacement of hnRNP A2 from BC1 RNA by lgG SLES1 and lgG SLE S6. Electrophoretic mobility levels are indicated to the left of the autoradiogram as follows: mobility level I, BC1 RNA-lgG complexes; mobility level II, BC1 RNA-hnRNP A2 complexes; mobility level III, unbound BC1 RNA. ${ }^{32}$ P-labeled BC1 RNA was loaded in lanes 1-12 as follows. Lane 1, unbound BC1 RNA runs with high mobility. Lane 2, BC1 RNA incubated with hnRNP A2; reduced mobility indicates BC1 RNA-hnRNP A2 complex formation. Lane 3, BC1 RNA incubated with lgG SLE S1; reduced mobility indicates BC1 RNA-anti-BC antibody immune complex formation. Lane 4, BC1 RNA incubated with lgG SLE S6; reduced mobility indicates BC1 RNA-anti-BC antibody immune complex formation. Lane 5, BC1 RNA incubated with lgG HS4; same mobility as that of unbound BC1 RNA in lane 1 indicates lack of immune complex formation. Lane 6, BC1 RNA incubated with hnRNP A2 and, after 30 min, with lgG SLE S1; data indicate displacement of hnRNP A2 from BC1 RNA by IgG SLE S1. Lane 7, BC1 RNA incubated with hnRNP A2 and, after 30 min, with lgG SLE S6; data indicate displacement of hnRNP A2 from BC1 RNA by lgG SLE S6. Lane 8, BC1 RNA incubated with hnRNP A2 and, after 30 min, with lgG HS4; data indicate no displacement of hnRNP A2 from BC1 RNA by lgG HS4. Molar ratio of lgG to hnRNP A2 was 1:1. All final incubations were for 30 min. Lanes 10 -12: BC1 RNA was incubated with hnRNP A2 and, after $30 \mathrm{~min}$, with IgG SLE S6. Incubation was continued for the times indicated. The mobility shifts indicate complete displacement of hnRNP A2 from BC1 RNA by lgG SLE S6 within 60 min. B, Differential BC RNA complex formation with autoimmune lgGs. EMSA analysis was performed with ${ }^{32}$ P-labeled BC200 RNA, using lgG SLES1 and IgG SLE S6 (SLE patients), IgG HS4, lgG MS1 (MS patient), and lgG RA1 (RA patient). Shifts to lower mobility occur with lgG SLES1 and lgG SLE S6, but not with lgG HS4, lgG MS1, or lgG RA1, indicating that only SLE IgGs but not IgGs from HS or from non-SLE autoimmune disease patients react with BC200 RNA to form immune complexes.

In a second set of experiments, we used radiolabeled human BC200 RNA for microinjection of cultured neurons after bathapplication of IgGs (Fig. 10). Results obtained in these experiments were analogous to those obtained with rat $\mathrm{BC} 1$ RNA. BC200 RNA was delivered along the entire dendritic extent after bath application of IgG HS4 (Fig. 10A,B) or IgG MS1 (Fig. 10E,F). By contrast, dendritic targeting was significantly reduced after bath application of IgG SLE S1 (Fig. $10 C, D$ ). Quantitative analysis (Fig. 10G) was performed using one-way ANOVA followed by Dunnett's test [comparison of dendritic BC200 RNA levels after bath application of IgG HS4
(Fig. 10A,B) with levels after bath application of IgG SLE S1 (Fig. 10C,D), $p<0.0001$ for all interval points; comparison with levels after bath application of IgG MS1 (Fig. 10E,F), $p>$ 0.73 for all interval points].

We conclude from the above results that bath-applied IgGs are taken up by cultured neurons, and that anti-BC IgGs from SLE patients thus internalized are able to interfere with the dendritic delivery of rat BC1 RNA and human BC200 RNA. By contrast, delivery of BC1 RNA or BC200 RNA to synapto-dendritic domains appears unaffected when IgGs from non-SLE subjects (including HS as well as MS patients and RA patients) are used in 

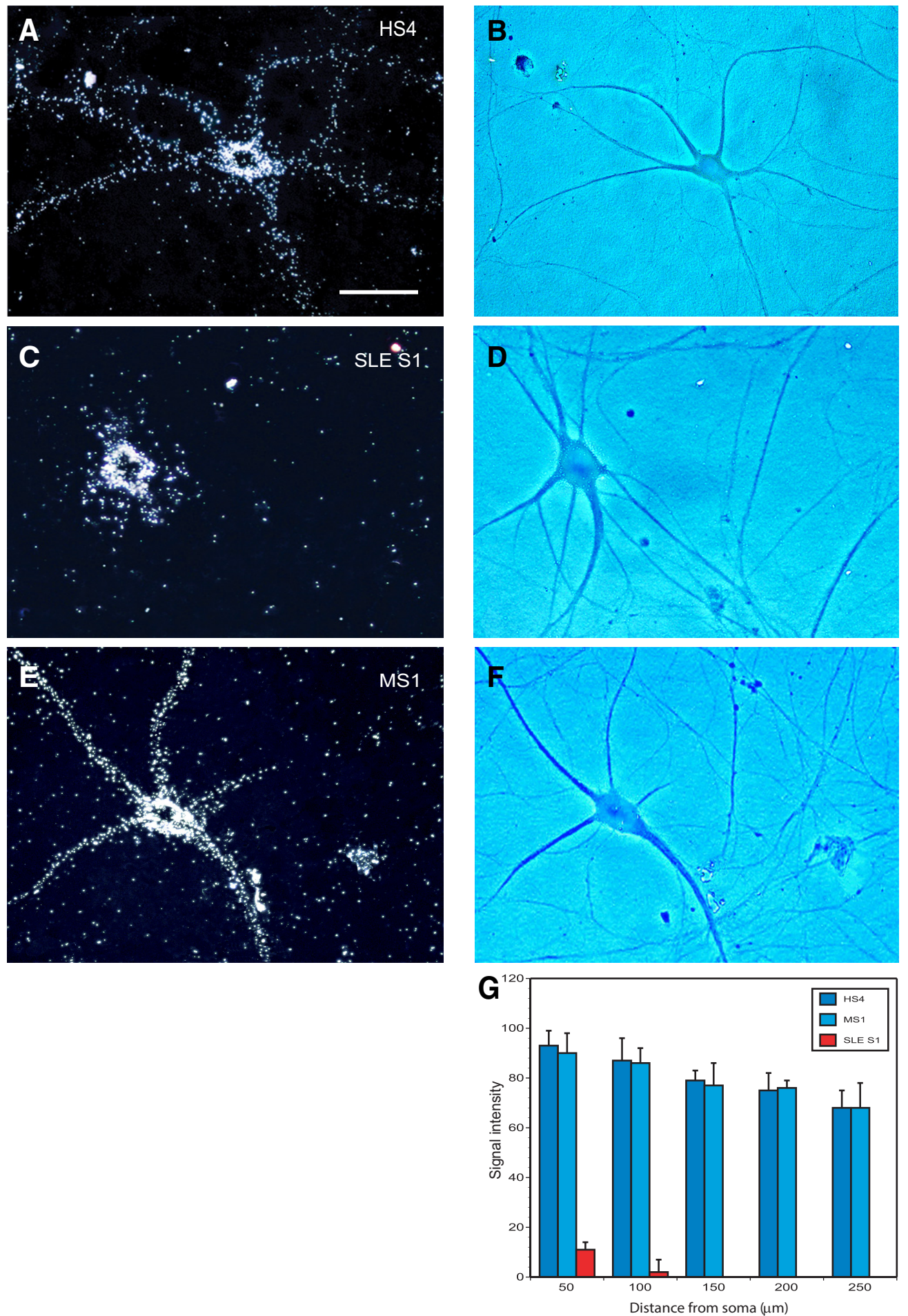

Figure 7. Dendritic transport of rat BC1 RNA: impairment after coinjection with SLE anti-BC IgGs. After preincubation with IgGs, radiolabeled BC1 RNA was coinjected into sympathetic neurons in primary culture. Coinjection was performed with $\lg G \mathrm{HS} 4(\boldsymbol{A}, \boldsymbol{B}), \operatorname{lgGSLES1}(\boldsymbol{C}, \boldsymbol{D})$, or $\operatorname{lgG} \mathrm{MS1}(\boldsymbol{E}, \boldsymbol{F})$. In dark-field photomicrographs $(\boldsymbol{A}, \boldsymbol{C}, \boldsymbol{E})$, labeling signal appears as white silver grains. Typical neuronal morphology and dendritic extent of sympathetic neurons in culture (Muslimov et al., 2011, 2014) are observed in phase-contrast photomicrographs $\boldsymbol{B}$ (corresponding to dark-field photomicrograph $\boldsymbol{A}$ ), $\boldsymbol{D}$ (corresponding to dark-field photomicrograph $\boldsymbol{C}$ ), and $\boldsymbol{F}$ (corresponding to dark field photomicrograph $\boldsymbol{E}$ ). Scale bar, $50 \mu \mathrm{m}$. Numbers of cells analyzed: $\boldsymbol{A}, \boldsymbol{B}, 7$ neurons, 28 dendrites; $\boldsymbol{C}, \boldsymbol{D}, 8$ neurons, 28 dendrites; and $\boldsymbol{E}, \boldsymbol{F}, 7$ neurons, 28 dendrites. Quantitative analysis ( $\boldsymbol{G}$ ) indicates that lgG SLES1, but not lgG HS4 or lgG MS1, significantly reduces dendritic delivery of BC1 RNA.

coinjection or bath-application approaches. The combined data indicate that SLE anti-BC IgGs, recognizing 5' dendritic targeting elements and competing with hnRNP A2, specifically disrupt delivery of regulatory BC RNAs to dendrites.

\section{SLE anti-BC abs: mislocalization of BC1 RNA in vivo}

The above results indicate that SLE anti-BC abs are internalized by neurons in primary culture, after which they interfere with BC RNA dendritic localization. We next asked whether in vivo, cir- 

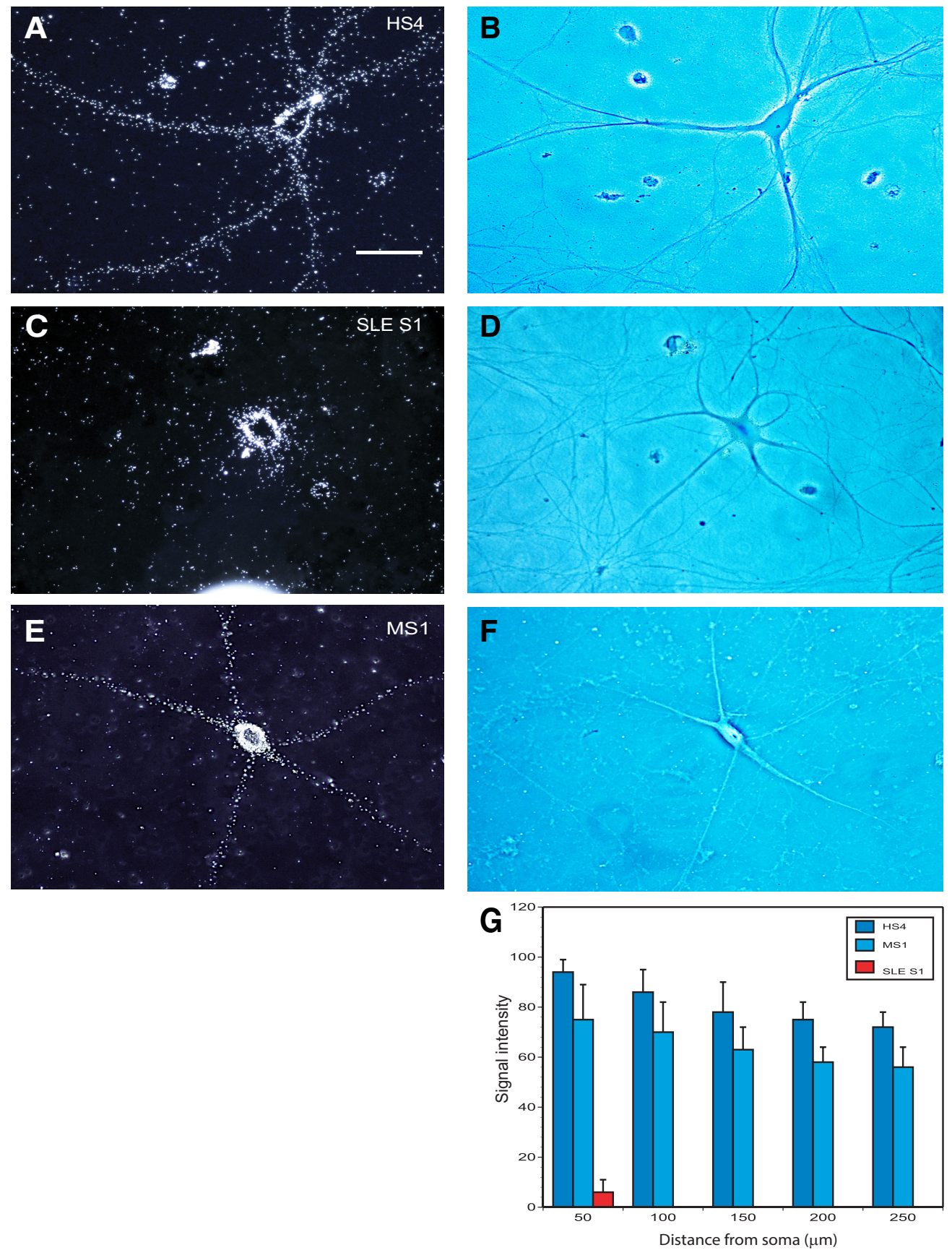

Figure 8. Dendritic transport of human BC200 RNA: impairment after coinjection with SLE anti-BC IgGs. Coinjection was performed, as described for Figure 7, with IgG HS4 (A, B), IgG SLE S1 (C, $\boldsymbol{D})$, or lgG MS1 $(\boldsymbol{E}, \boldsymbol{F})$. Dark-field photomicrographs $(\boldsymbol{A}, \boldsymbol{C}, \boldsymbol{E})$ are accompanied by corresponding phase-contrast photomicrographs $(\boldsymbol{B}, \boldsymbol{D}, \boldsymbol{F})$. Scale bar, $50 \mu \mathrm{m}$. Number of cells analyzed: $\boldsymbol{A}, \boldsymbol{B}, 9$ neurons, 33 dendrites; $\boldsymbol{C}, \boldsymbol{D}, 8$ neurons, 28 dendrites; and $\boldsymbol{E}, \boldsymbol{F}, 7$ neurons, 27 dendrites. Quantitative analysis (G) indicates that $\lg G$ SLES1, but not lgG HS4 or lgG MS1, significantly reduces dendritic delivery of BC200 RNA.

culating antibodies can gain access to the brain and are internalized by neurons in sufficient concentrations to impact dendritic localization of endogenous BC1 RNA. This issue was addressed by intravenous injections of mice in which purified SLE anti-BC IgGs or purified other, non-SLE IgGs were injected intravenously as described previously (Kowal et al., 2006; see also Materials and Methods). Each intravenous injection of IgG was directly followed by an intraperitoneal injection of LPS (Kowal et al., 2006). LPS was applied to breach the BBB and thus to allow injected, circulating IgGs access to the brain (Kowal et al., 2004, 2006; Mader et al., 2017). Another round of LPS intraperitoneal injec- tions was performed $48 \mathrm{~h}$ later. Animals were killed after 2 more days and their brains processed for in situ hybridization directed at endogenous BC1 RNA.

Figure 11 shows that in hippocampal area CA1, the distribution of $\mathrm{BC} 1 \mathrm{RNA}$ is normal after intravenous injection of $\mathrm{IgG}$ HS4, i.e., purified IgG from an HS. Thus, in this case, robust BC1 RNA signal intensities are detectable in synapto-dendritic strata oriens and radiatum, with signal intensities similar to those in somatic stratum pyramidale (Fig. $11 A, B$ ). This result reflects an enrichment of BC1 RNA in dendritic arborizations of CA1 pyramidal cells, as has previously been reported for WT rats (Lin et al., 

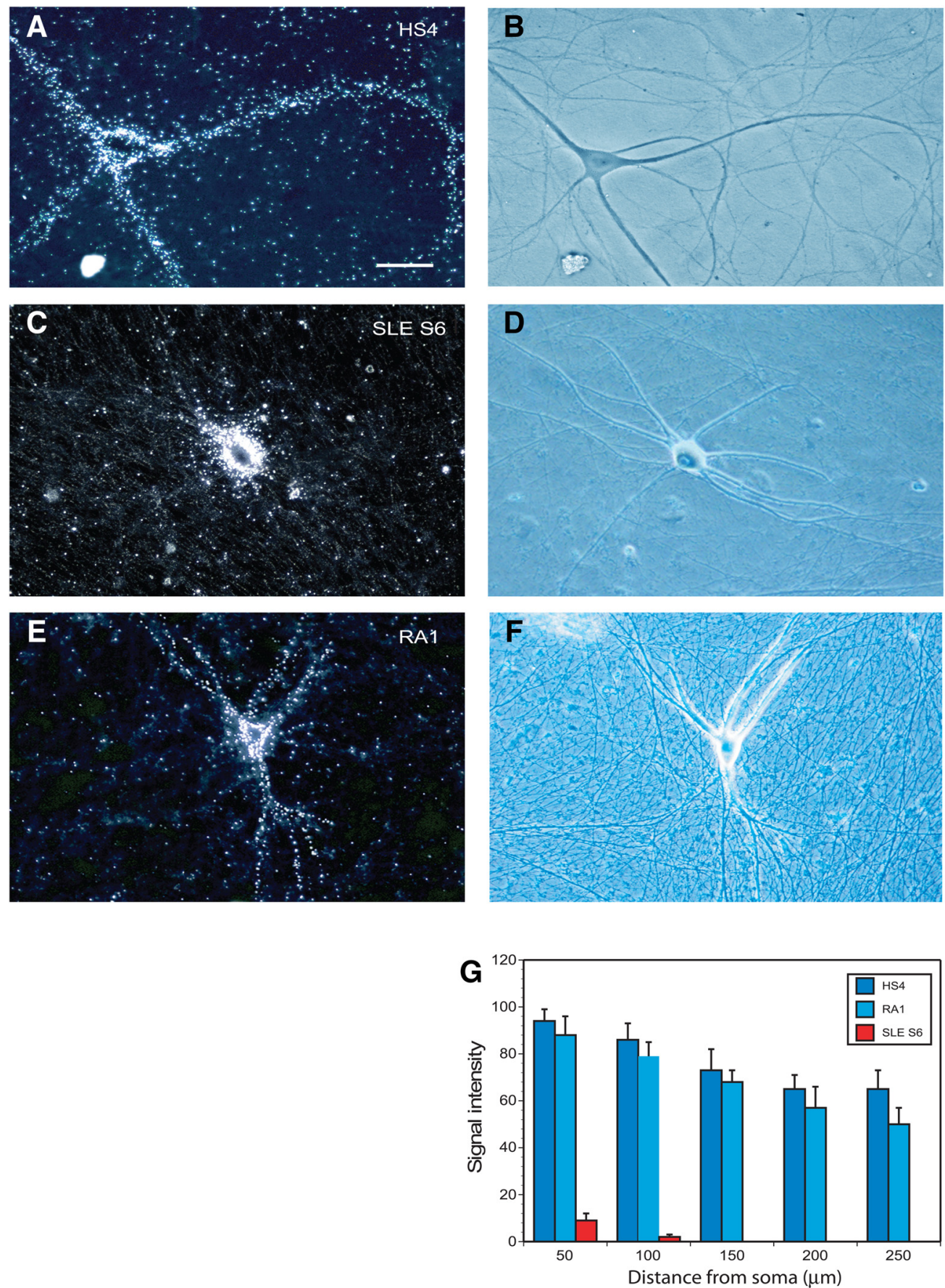

Figure 9. Dendritic transport of rat BC1 RNA: impairment after bath application of SLE anti-BC IgGs. Sympathetic neurons were microinjected with radiolabeled BC1 RNA after bath application of IgGs for $8 \mathrm{~h}$. Bath application was performed with $\lg G \mathrm{HS} 4(\boldsymbol{A}, \boldsymbol{B})$, IgG SLE S6 (C, D), or lgG RA1 $(\boldsymbol{E}, \boldsymbol{F})$. Dark-field photomicrographs $(\boldsymbol{A}, \boldsymbol{C}, \boldsymbol{E})$ are accompanied by corresponding phase-contrast photomicrograph $(\boldsymbol{B})$, DIC Nomarski photomicrograph (D),and phase-contrast photomicrograph $(\boldsymbol{F})$. Scale bar, $50 \mu \mathrm{m}$. Number of cells analyzed: $\boldsymbol{A}, \boldsymbol{B}, 8$ neurons, 28 dendrites; $\boldsymbol{C}, \boldsymbol{D}, 7$ neurons, 28 dendrites; and $\boldsymbol{E}, \boldsymbol{F}, 8$ neurons, 27 dendrites. Quantitative analysis $(\boldsymbol{G})$ indicates that bath-applied lgG SLE S6, but not bath-applied IgG HS4 or lgG RA1, significantly reduces dendritic delivery of BC1 RNA.

2001) and mice (Muslimov et al., 2018). In striking contrast, in CA1 of mice injected with IgG SLE S1, the distribution of the BC1 RNA labeling signal was significantly increased in somatic stratum pyramidale and significantly decreased in synapto-dendritic strata oriens and radiatum (Fig. 11C,D). These results indicate (1) that injected antibodies were able to cross the BBB and enter neurons, and (2) that purified IgG from an SLE patient with neuropsychiatric manifestations, but not IgG from an HS, prevented BC1 RNA from significantly localizing to CA1 pyramidal cell dendrites, thus causing its accumulation in neuronal cell bodies.

The above qualitative observations were further confirmed by quantitative analysis of BC1 RNA labeling intensities in strata oriens, pyramidale, and radiatum obtained from animals injected with SLE anti-BC abs ( $n=12$; see Materials and Methods) and those obtained from animals injected with non-SLE abs $(n=10)$ (Fig. $11 E, F$ ). One-way ANOVA was followed by Tukey's multiplecomparisons test in which signal intensities in stratum pyrami- 

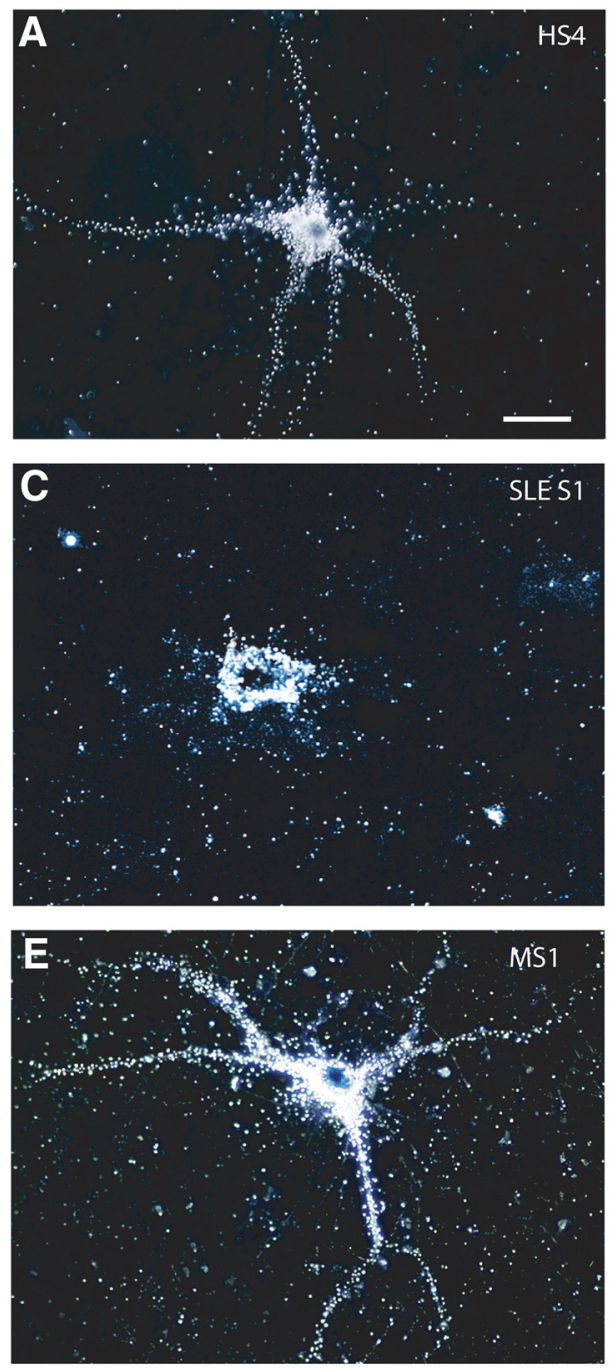
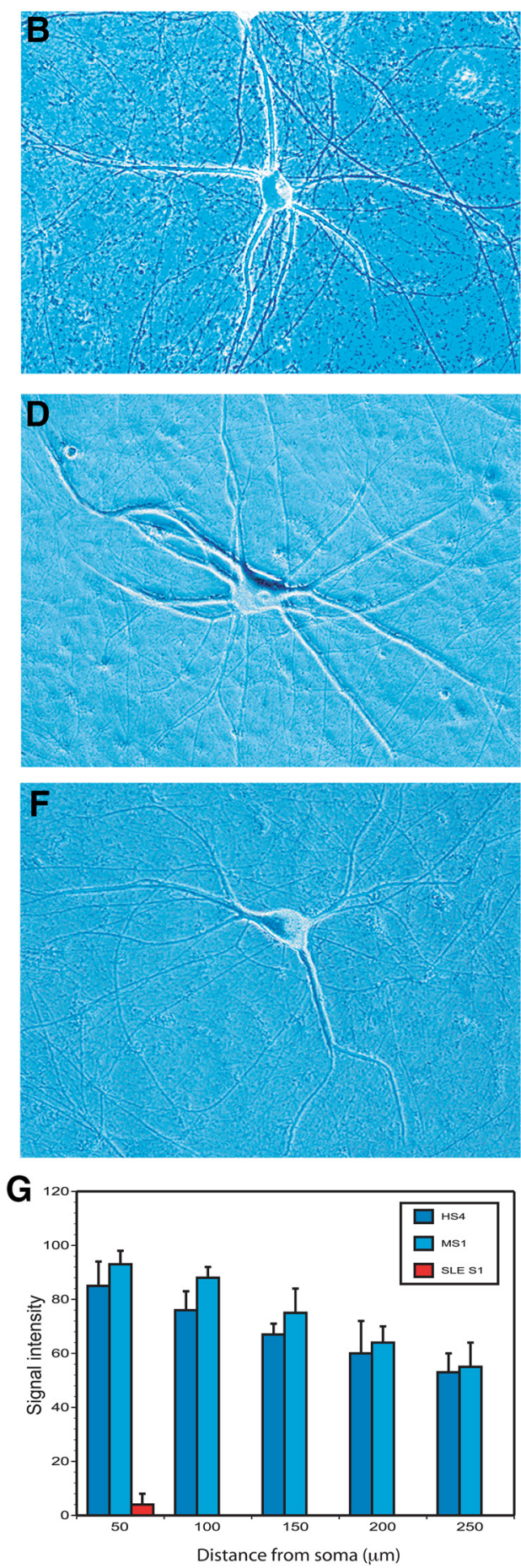

Figure 10. Dendritic transport of human $B C 200$ RNA: impairment after bath application of SLE anti-BC lgGs. Bath application was performed with $\lg G H S 4(\boldsymbol{A}, \boldsymbol{B}), \lg G S L E S 1(C, D)$, or lgG MS1 (E, $F)$. Dark-field photomicrographs $(\boldsymbol{A}, \boldsymbol{C}, \boldsymbol{E})$ are accompanied by phase-contrast $(\boldsymbol{B})$ and DIC Nomarski $(\boldsymbol{D}, \boldsymbol{F})$ photomicrographs. Scale bar, $50 \mu \mathrm{m}$. Number of cells analyzed: $\boldsymbol{A}, \boldsymbol{B}, 8$ neurons, 32 dendrites; $\boldsymbol{C}, \boldsymbol{D}, 7$ neurons, 28 dendrites; $\boldsymbol{E}, \boldsymbol{F}, 7$ neurons, 27 dendrites. Quantitative analysis (G) indicates that bath-applied lgG SLES1, but not bath-applied lgG HS4 or lgG MS1, significantly reduces dendritic delivery of BC200 RNA.

dale (center), in stratum oriens at a distance of $50 \mu \mathrm{m}$ from edge of stratum pyramidale, and in stratum radiatum at distances of 50,100, and $150 \mu \mathrm{m}$ from edge of stratum pyramidale, were compared between animals injected with SLE anti-BC abs and those injected with non-SLE abs: $p<0.0001$ for all sample points.

In CA1 of animals injected with non-SLE abs (Fig. 11E), signal intensities in stratum pyramidale tended to be lower than those in neighboring strata oriens and radiatum (one-way ANOVA, $p=0.043$ ). Post hoc analysis using Dunnett's multiple-comparisons test revealed that signal intensities in stratum pyramidale were significantly lower than those in stratum radiatum at $150 \mu \mathrm{m}(p=0.018)$ but not significantly lower than those in stratum radiatum at $50 \mu \mathrm{m}(p=0.067)$, those in stratum radiatum at $100 \mu \mathrm{m}(p=0.349)$, or those in stratum oriens at $50 \mu \mathrm{m}(p=0.71)$. By contrast, in CA1 of 

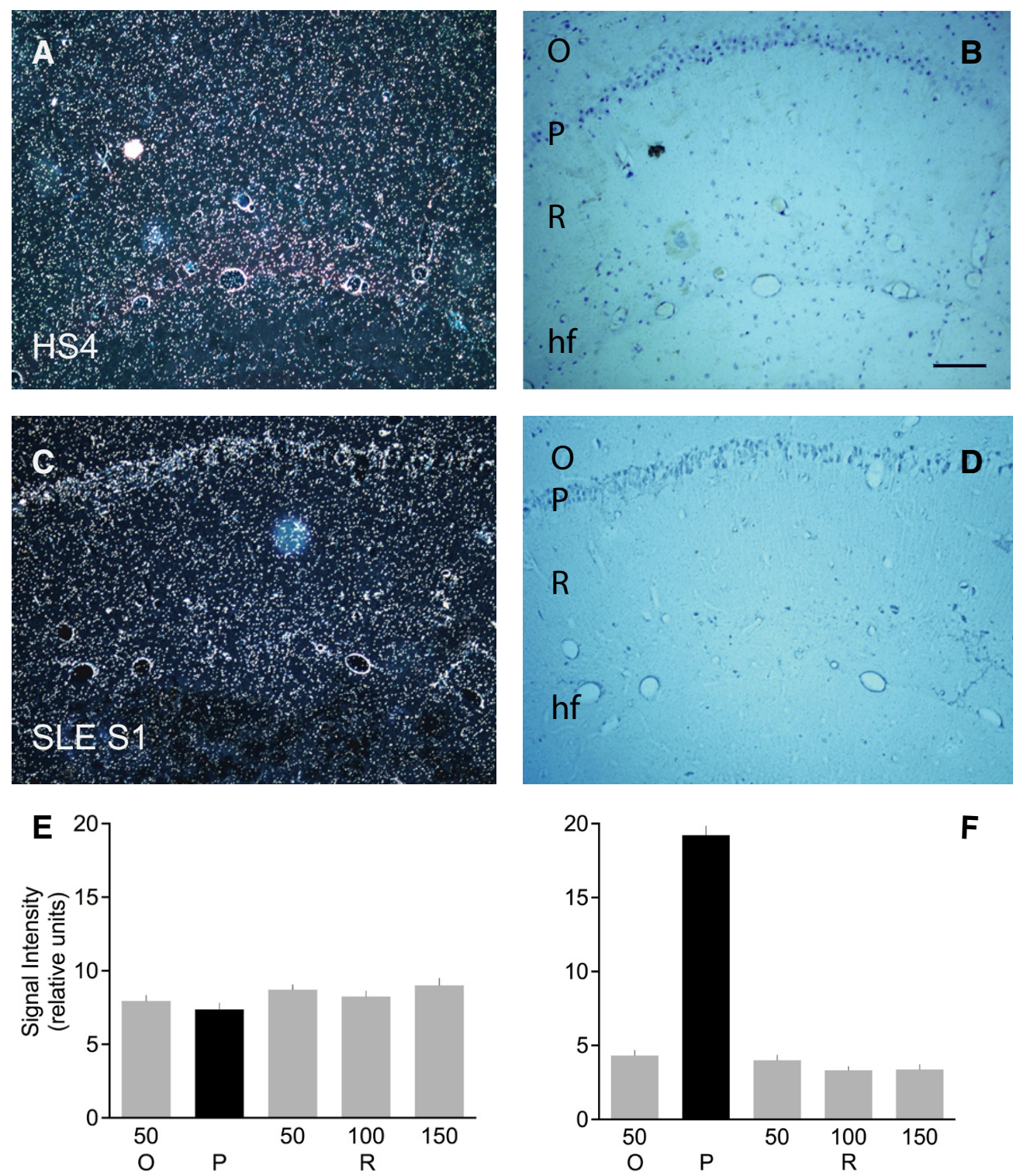

Figure 11. SLE anti-BC abs: mislocalization of endogenous BC1 RNA in vivo. Mice were injected intravenously with SLE anti-BC abs or with non-SLE abs and, subsequently, intraperitoneally with LPS to permeabilize the BBB (Kowal et al., 2006). The following antibodies were used: SLES1, SLE S6, HS4, MS1, and RA (see Materials and Methods for numbers of animals used per antibody). 0 , Stratum oriens; $P$, stratum pyramidale; $R$, stratum radiatum; hf, hippocampal fissure. $\boldsymbol{A}-\boldsymbol{D}$, Hippocampal CA1 regions (coronal sections) of injected animals are shown in dark-field ( $\boldsymbol{A}, \boldsymbol{C}$ ) and corresponding bright-field $(\boldsymbol{B}, \boldsymbol{D})$ photomicrographs. Scale bar, $100 \mu \mathrm{m}$. BC1 RNA labeling signal is apparent as white silver grains, resulting from emulsion autoradiography, in dark-field photomicrographs. $A, B, C A 1$ region of an animal injected with lgG HS4 (i.e., from an HS). BC1 RNA labeling signal is robust in dendritic layers stratum oriens and stratum radiatum. C, D, CA1 region of an animal injected with IgG SLES1 (i.e., from an SLE patient with seizures). BC1 RNA labeling signal is prominent in somatic layer stratum pyramidale. E, $F$, Quantitative analysis. Autoradiographic signal intensities were established in stratum pyramidale (center), in stratum oriens at a distance of $50 \mu \mathrm{m}$ from the edge of stratum pyramidale, and in stratum radiatum at distances of 50 , 100 , and $150 \mu \mathrm{m}$ from the edge of stratum pyramidale. $\boldsymbol{E}$, Animals injected with non-SLE abs (10 animals). $\boldsymbol{F}$, Animals injected with SLE anti-BC abs ( $n=12$ animals).

animals injected with SLE anti-BC abs (Fig. $11 F$ ), signal intensities in stratum pyramidale were significantly higher than those in neighboring strata oriens and radiatum (one-way ANOVA followed by Dunnett's multiple-comparisons test of strata pyramidale versus oriens and radiatum at above distances: $p<0.0001$ for all sample points).

In conclusion the above in vivo data indicate that after entering the brain (by crossing the LPS-breached BBB) and being taken up by neurons, SLE anti-BC abs can target BC1 RNA and interfere with its localization to synapto-dendritic domains.

\section{Discussion}

BC RNAs constitute a small group of scRNAs of which rodent BC1 RNA and primate BC200 RNA have been most extensively investigated (for review, see Iacoangeli and Tiedge, 2013; Eom et al., 2018). Neuronal BC1 and BC200 RNAs are translational regulators that operate in the activity-dependent control of local protein synthesis in synapto-dendritic domains (Eom et al., 2011, 2014, 2018). Translational control competence resides in BC1 and BC200 RNA 3' stem-loop domains which contain identical C-loop motif structures (Eom et al., 2011). The BC RNA 3' C-loop motifs feature noncanonical nucleotide interactions of the $\mathrm{A} \cdot \mathrm{A}$ trans-WC/Hoogsteen and of the $\mathrm{C} \cdot \mathrm{A}$ cis-WC/sugar edge subtypes. These $\mathrm{C}$-loop motif noncanonical interactions are requisite for high-affinity binding to eIF4B and translational control competence (Eom et al., 2011, 2014; Iacoangeli and Tiedge, 2013). 


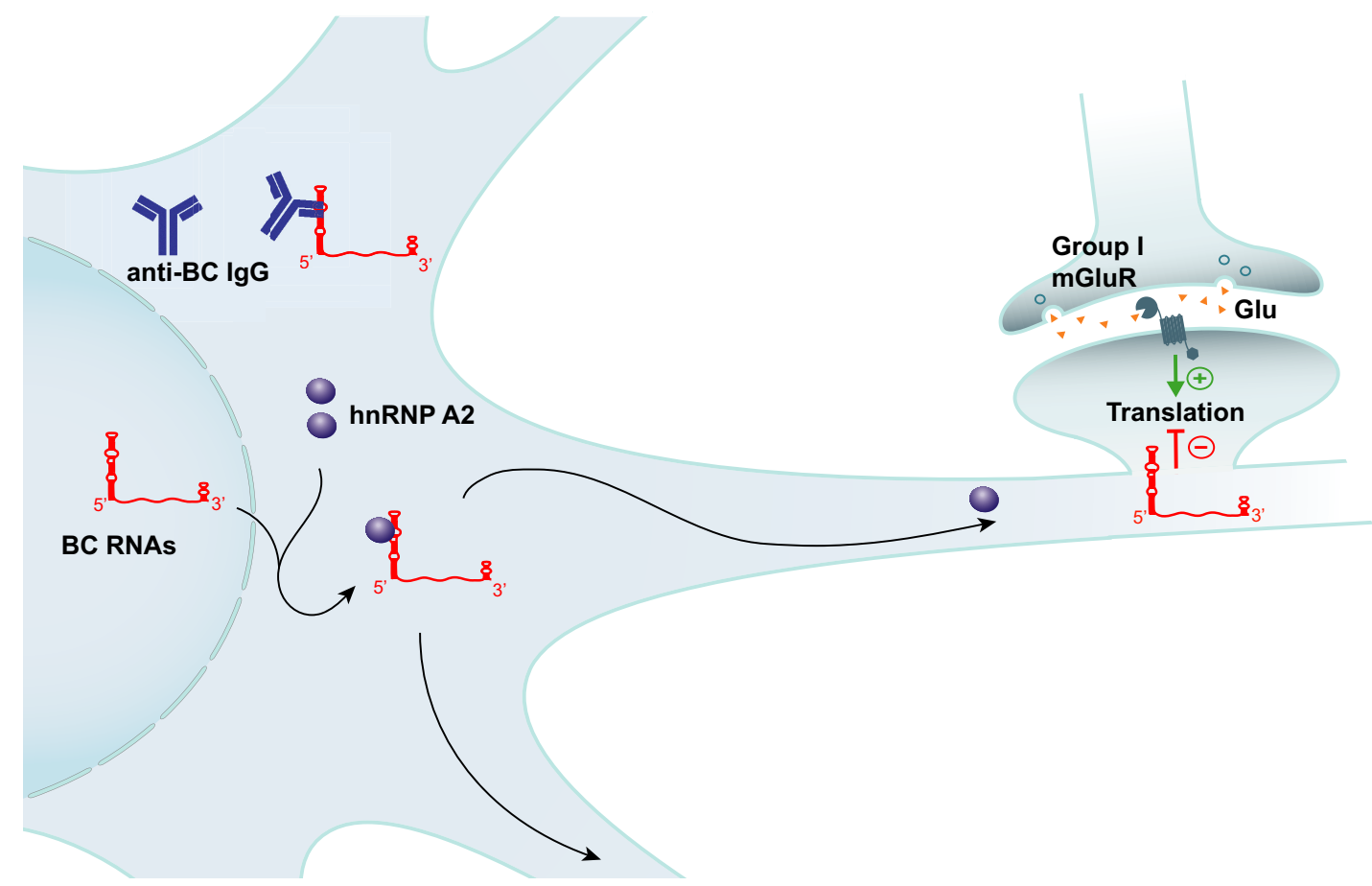

Figure 12. SLEanti-BC abs in neurons. Delivery of $B C$ RNAs to synapto-dendritic domains requires transport factor hnRNPA2. The factor interacts with targeting-determinant $G A$ motifs contained within BC RNA 5' stem-loop domains. SLE anti-BC IgGs bind to the same motif structures, displacing hnRNP A2 from BC RNAs and as a result causing impaired dendritic delivery.

Extending this analogy, the BC1 and BC200 RNA 5' stemloop domains harbor similar GA motif structures (Skryabin et al., 1998; Muslimov et al., 2006, 2011; Iacoangeli and Tiedge, 2013; Eom et al., 2018). The noncanonical BC RNA GA motifs act as spatial codes to specify dendritic targeting (Muslimov et al., 2006, 2011; Iacoangeli and Tiedge, 2013; Eom et al., 2018). The BC1 RNA 5' GA motif features tandem $\mathrm{G} \cdot \mathrm{A} / \mathrm{A} \cdot \mathrm{G}$ pairings, in the transHoogsteen/sugar edge hydrogen bonding format, that are required for dendritic delivery (Lescoute et al., 2005; Muslimov et al., 2006). BC1 RNA U22 also contributes to dendritic targeting competence, whereas a basal internal loop does not (Muslimov et al., 2006). In addition, work with transgenic mouse lines expressing mutant BC1 RNAs has confirmed a 5' DTE requirement for dendritic localization (Robeck et al., 2016). However, apparent methodological insufficiencies have been noted (Eom et al., 2018; see also technical comment published online with Robeck et al., 2016).

In the design of our experimental approach, we took into consideration the following information (see also introduction). First, because BC1 RNA and BC200 RNA are functional analogs rather than phylogenetic orthologs, it was important to establish whether interactions of the two RNAs with SLE anti-BC abs are similarly analogous. For this reason, molecular and cellular experiments were performed with BC1 RNA and BC200 RNA in parallel. Second, since BC1 and BC200 RNAs, because of their distinct phylogenetic background, feature unrelated primary structures but, as a result of retroposition-mediated functional convergence (Iacoangeli and Tiedge, 2013), identical or similar higher-order-structure architectural motifs, we surmised that any anti-BC ab recognizing both RNAs would recognize such motifs rather than nucleotide sequences.

We found that SLE anti-BC RNA autoimmune antibodies do in fact recognized both BC RNAs as an SLE anti-BC ab recognizing BC200 RNA would also recognize BC1 RNA, albeit at lower reactivity. This result suggests that the $\mathrm{BC} 1-\mathrm{BC} 200$ functionalmechanistic analogy (Iacoangeli and Tiedge, 2013; Eom et al.,
2018) is also maintained with respect to autoantibody interactions. This functional correspondence extends even further as SLE anti-BC abs target mechanistically analogous doublestranded RNA motif structures. Reactivity of anti-BC abs was found directed at BC1 and BC200 RNA 5' DTE stem-loop domains, structural elements that constitute the "transport centers" of BC RNAs as they carry spatial codes to specify dendritic delivery (Muslimov et al., 2006, 2011, 2018; Iacoangeli and Tiedge, 2013; Eom et al., 2018).

SLE anti-BC abs thus engage the $5^{\prime}$ transport centers of BC RNAs (rather than their 3' business centers, the C-loop motifs that mediate translational control). In the 5' BC1 DTE, GA motif noncanonical purine purine pairings, together with unpaired nucleotide U22, are required for SLE autoantibody recognition. Precisely the same structural attributes have previously been identified as requisite determinants of dendritic targeting competence (Muslimov et al., 2006, 2011). Transport factor hnRNP $\mathrm{A} 2$, essential for BC RNA dendritic targeting, specifically interacts with 5' noncanonical GA motif structures (Muslimov et al., 2011). We now find that SLE anti-BC IgGs compete with hnRNP A2 for access to BC RNAs, effectively displacing the transport factor at a 1:1 molar ratio.

Molecular competition between SLE anti-BC abs and hnRNP A2 is of immediate functional relevance as it predicts BC RNA transport impairments as a consequence of the transport factor's diminished ability to access 5' DTE structures. RNA transport assays corroborated this hypothesis: SLE anti-BC abs significantly decreased dendritic delivery of both BC1 and BC200 RNAs. Two types of experimental approaches were performed. (i) BC RNAs were preincubated with SLE anti-BC IgGs or other IgGs, before comicroinjection into cultured neurons. (ii) Cultured neurons were preincubated with SLE anti-BC IgGs or other IgGs, by bath application, before BC RNA microinjection. In either approach, application of SLE anti-BC IgGs resulted in significantly reduced dendritic delivery of $\mathrm{BC} 1$ and $\mathrm{BC} 200 \mathrm{RNAs}$. The data are in agree- 
ment with accumulating evidence showing that neurons internalize IgGs via clathrin-dependent Fc $\gamma$ receptor-mediated endocytosis, that such internalization is requisite for the clearance of intracellular antigens, and that internalized autoantibodies have the potential to disrupt intracellular functions (Elkon and Casali, 2008; Congdon et al., 2013; Douglas et al., 2013; Kazim et al., 2017; Rhodes and Isenberg, 2017). In the case of SLE anti-BC IgGs, intracellular molecular mechanisms are impacted as RNA transport factor hnRNP A2 is displaced from BC RNA DTEs, a displacement that causes RNA mislocalization as BC RNAs are now predominantly retained in neuronal somata rather than being delivered to synapto-dendritic domains (Fig. 12).

In in vivo experiments with mice, we applied LPS to permeabilize the BBB (Kowal et al., 2004, 2006) and injected autoimmune and other antibodies intravenously. SLE anti-BC abs, but not non-SLE abs, caused a significant change in the somatodendritic distribution of endogenous BC1 RNA in hippocampal CA1: BC1 RNA, normally present at robust levels in dendritic domains, now collapsed back into a predominantly somatic localization. Because SLE anti-BC abs, but not non-SLE abs, target BC RNA DTEs and prevent transport factor hnRNP A2 from DTE binding, we suggest that intravenous injected abs reach the CNS where they are taken up by neurons, after which SLE anti-BC abs but not non-SLE abs prevent anterograde delivery of endogenous BC1 RNA to synapto-dendritic domains. Such failure to deliver, together with clearance of preexisting endogenous BC1 RNA from dendritic domains (by mechanisms that remain to be established), results in significantly diminished synaptodendritic localization and substantial mislocalization of the RNA to somatic domains.

The absence, or severely reduced presence, of regulatory BC RNAs in synapto-dendritic domains is expected to give rise to phenotypic alterations that are similar to, but possibly milder than, those observed in the BC1 KO animal model. Global lack of BC1 RNA in such animals causes neuronal hyperexcitability that manifests in the form of prolonged epileptiform discharges in slice preparations and seizure susceptibility in vivo, as well as cognitive impairment (Zhong et al., 2009, 2010; Chung et al., 2017; Iacoangeli et al., 2017). Identical or similar phenotypic alterations have been observed in the CGG-repeat animal model (Muslimov et al., 2018). In these animals, generated as a model for the fragile X premutation disorder (Bontekoe et al., 2001), the 5' UTR of Fmr1 mRNA harbors expanded CGG triplet repeats in the range of 55-200 units (Oostra and Willemsen, 2009). Phenotypic hallmarks of the fragile $\mathrm{X}$ premutation disorder include epilepsy and cognitive impairment in young patients and neurodegeneration and motor dysfunction in advanced-age patients. (Hagerman et al., 2010, 2016; Hagerman, 2013). Our previous work (Muslimov et al., 2011, 2018) has shown that expanded CGG repeats, which form noncanonical stem-loop structures featuring purine purine base pairs, sequester transport factor hnRNP A2 and cause significantly reduced synapto-dendritic delivery of BC1 RNA in vivo. Thus, epilepsy and cognitive impairment in young CGG-repeat animals are consequential to BC1 RNA dendritic transport deficits and subcellular mislocalization (Muslimov et al., 2018).

We conclude that BC RNA mislocalization can be caused by reduced functional availability of hnRNP A2 as a result of CGGrepeat competition (fragile $\mathrm{X}$ premutation) or of anti-BC autoantibody competition (SLE). Epilepsy and cognitive impairment are phenotypic consequences of either type of competition. Such overall correspondence notwithstanding, important differences are noted as SLE clinical presentations have been known to be notoriously diverse (Mader et al., 2017). Several underlying causes, not mutually exclusive, may contribute to this diversity. While auto-IgGs are taken up via Fc $\gamma$ receptor-mediated endocytosis (Elkon and Casali, 2008; Congdon et al., 2013; Douglas et al., 2013; Kazim et al., 2017; Rhodes and Isenberg, 2017), the efficiency of this mechanism may vary among neuronal cell types. Autoantibodies have to traverse a compromised BBB for access to CNS neurons (Abbott et al., 2003; Mader et al., 2017). Depending on the nature and location of BBB disruption(s), SLE autoantibody-impacted CNS areas and resulting neurological symptoms may vary. Finally, low-level crossreactivity was observed with U4 snRNA, raising the question of whether phenotypic consequences may also result from engaging spliceosomal U4 RNA in addition to BC RNAs.

Why are SLE anti-BC abs directed at BC RNA $5^{\prime}$ transport centers but not at $3^{\prime}$ business centers? We speculate that $5^{\prime} \mathrm{GA}$ motifs, but not 3' C-loop motifs, resemble viral RNA structures and may thus be mistaken for "nonself" intruders. The HIV Rev response element stem-loop IIb, for example, contains a noncanonical RNA motif with $\mathrm{G} \cdot \mathrm{A}$ and $\mathrm{G} \cdot \mathrm{G}$ base pairings (Jain and Belasco, 1996). The similarity to BC RNA GA motifs may "deceive" an immune system into treating BC RNAs as inherently nonself. Alternatively, a viral infection may trigger an antiviral RNA immune response with significant and potentially longlasting crossreactivity against BC RNAs. We propose that such molecular mimicry (Mader et al., 2017) may underlie anti-RNA autoimmune responses in general.

\section{References}

Abbott NJ, Mendonça LL, Dolman DE (2003) The blood-brain barrier in systemic lupus erythematosus. Lupus 12:908-915.

American College of Rheumatology (1999) The American College of Rheumatology nomenclature and case definitions for neuropsychiatric lupus syndromes. Arthritis Rheum 42:599-608.

Arbuckle MR, McClain MT, Rubertone MV, Scofield RH, Dennis GJ, James JA, Harley JB (2003) Development of autoantibodies before the clinical onset of systemic lupus erythematosus. N Engl J Med 349:1526-1533.

Barrat FJ, Elkon KB, Fitzgerald KA (2016) Importance of nucleic acid recognition in inflammation and autoimmunity. Annu Rev Med 67:323336.

Bontekoe CJ, Bakker CE, Nieuwenhuizen IM, van der Linde H, Lans H, de Lange D, Hirst MC, Oostra BA (2001) Instability of a (CGG) ${ }_{98}$ repeat in the Fmr1 promoter. Hum Mol Genet 10:1693-1699.

Briz V, Restivo L, Pasciuto E, Juczewski K, Mercaldo V, Lo AC, Baatsen P, Gounko NV, Borreca A, Girardi T, Luca R, Nys J, Poorthuis RB, Mansvelder HD, Fisone G, Ammassari-Teule M, Arckens L, Krieger P, Meredith R, Bagni C (2017) The non-coding RNA BC1 regulates experience-dependent structural plasticity and learning. Nat Commun 8:293.

Chu JL, Brot N, Weissbach H, Elkon K (1991) Lupus antiribosomal P antisera contain antibodies to a small fragment of $28 \mathrm{~S}$ rRNA located in the proposed ribosomal GTPase center. J Exp Med 174:507-514.

Chung A, Dahan N, Alarcon JM, Fenton AA (2017) Effects of regulatory BC1 RNA deletion on synaptic plasticity, learning, and memory. Learn Mem 24:646-649.

Cimaz R, Guerrini R (2008) Epilepsy in lupus. Lupus 17:777-779.

Congdon EE, Gu J, Sait HB, Sigurdsson EM (2013) Antibody uptake into neurons occurs primarily via clathrin-dependent Fc $\gamma$ receptor endocytosis and is a prerequisite for acute tau protein clearance. J Biol Chem 288:35452-35465.

Crow MK (2010) Long interspersed nuclear elements (LINE-1): potential triggers of systemic autoimmune disease. Autoimmunity 43:7-16.

DeChiara TM, Brosius J (1987) Neural BC1 RNA: cDNA clones reveal nonrepetitive sequence content. Proc Natl Acad Sci U S A 84:2624-2628.

Douglas JN, Gardner LA, Levin MC (2013) Antibodies to an intracellular antigen penetrate neuronal cells and cause deleterious effects. J Clin Cell Immunol 4:1-7. 
Elkon K, Casali P (2008) Nature and functions of autoantibodies. Nat Clin Pract Rheumatol 4:491-498.

Elkon KB, Bonfa E, Brot N (1992) Antiribosomal antibodies in systemic lupus erythematosus. Rheum Dis Clin North Am 18:377-390.

Eom T, Berardi V, Zhong J, Risuleo G, Tiedge H (2011) Dual nature of translational control by regulatory BC RNAs. Mol Cell Biol 31:45384549.

Eom T, Muslimov IA, Tsokas P, Berardi V, Zhong J, Sacktor TC, Tiedge H (2014) Neuronal BC RNAs cooperate with eIF4B to mediate activitydependent translational control. J Cell Biol 207:237-252.

Eom T, Muslimov IA, Iacoangeli A, Tiedge H (2018) Dendritic targeting and regulatory RNA control of local neuronal translation. In: The Oxford handbook of neuronal protein synthesis (Sossin W, ed). New York: OUP.

Goody TA, Melcher SE, Norman DG, Lilley DM (2004) The kink-turn motif in RNA is dimorphic, and metal ion-dependent. RNA 10:254-264.

Grandin K (2010) The Nobel Prizes 2009. Stockholm: Nobel Foundation.

Hagerman P (2013) Fragile X-associated tremor/ataxia syndrome (FXTAS): pathology and mechanisms. Acta Neuropathol 126:1-19.

Hagerman RJ, Wheeler A, Fitzpatrick S, Hunter J (2016) Premutationassociated disorders in hcildhood and adulthood. In: FXTAS, FXPOI, and other premutations disorders, Ed 2 (Tassone F, Hall DA, eds), pp 241262. Switzerland: Springer.

Hagerman R, Hoem G, Hagerman P (2010) Fragile X and autism: intertwined at the molecular level leading to targeted treatments. Mol Autism $1: 12$.

Hoet RM, Pieffers M, Stassen MH, Raats J, de Wildt R, Pruijn GJ, van den Hoogen F, van Venrooij WJ (1999) The importance of the light chain for the epitope specificity of human anti-U1 small nuclear RNA autoantibodies present in systemic lupus erythematosus patients. J Immunol 163: $3304-3312$

Iacoangeli A, Tiedge H (2013) Translational control at the synapse: role of RNA regulators. Trends Biochem Sci 38:47-55.

Iacoangeli A, Dosunmu A, Eom T, Stefanov DG, Tiedge H (2017) Regulatory BC1 RNA in cognitive control. Learn Mem 24:267-277.

Jain C, Belasco JG (1996) A structural model for the HIV-1 rev-RRE complex deduced from altered-specificity rev variants isolated by a rapid genetic strategy. Cell 87:115-125.

Joseph FG, Lammie GA, Scolding NJ (2007) CNS lupus: a study of 41 patients. Neurology 69:644-654.

Junghans RP, Anderson CL (1996) The protection receptor for IgG catabolism is the $\beta 2$-microglobulin-containing neonatal intestinal transport receptor. Proc Natl Acad Sci U S A 93:5512-5516.

Karaduman R, Fabrizio P, Hartmuth K, Urlaub H, Lührmann R (2006) RNA structure and RNA-protein interactions in purified yeast U6 snRNPs. J Mol Biol 356:1248-1262.

Kazim SF, Chuang SC, Zhao W, Wong RK, Bianchi R, Iqbal K (2017) Earlyonset network hyperexcitability in presymptomatic Alzheimer's disease transgenic mice is suppressed by passive immunization with anti-human APP/Abeta antibody and by mGluR5 blockade. Front Aging Neurosci 9:71.

Khanam T, Rozhdestvensky TS, Bundman M, Galiveti CR, Handel S, Sukonina V, Jordan U, Brosius J, Skryabin BV (2007) Two primate-specific small non-protein-coding RNAs in transgenic mice: neuronal expression, subcellular localization and binding partners. Nucleic Acids Res 35: 529-539.

Klein DJ, Schmeing TM, Moore PB, Steitz TA (2001) The kink-turn: a new RNA secondary structure motif. EMBO J 20:4214-4221.

Kondrashov AV, Kiefmann M, Ebnet K, Khanam T, Muddashetty RS, Brosius J (2005) Inhibitory effect of naked neural BC1 RNA or BC200 RNA on eukaryotic in vitro translation systems is reversed by poly(A)-binding protein (PABP). J Mol Biol 353:88-103.

Kowal C, DeGiorgio LA, Nakaoka T, Hetherington H, Huerta PT, Diamond B, Volpe BT (2004) Cognition and immunity; antibody impairs memory. Immunity 21:179-188.

Kowal C, Degiorgio LA, Lee JY, Edgar MA, Huerta PT, Volpe BT, Diamond B (2006) Human lupus autoantibodies against NMDA receptors mediate cognitive impairment. Proc Natl Acad Sci U S A 103:19854-19859.

Lamon EW, Bennett JC (1970) Antibodies to ribosomal ribonucleic acid (rRNA) in patients with systemic lupus erythematosus (SLE). Immunology 19:439-442.

Leontis NB, Lescoute A, WesthofE (2006) The building blocks and motifs of RNA architecture. Curr Opin Struct Biol 16:279-287.
Lescoute A, Leontis NB, Massire C, Westhof E (2005) Recurrent structural RNA motifs, Isostericity Matrices and sequence alignments. Nucleic Acids Res 33:2395-2409.

Lin D, Pestova TV, Hellen CU, Tiedge H (2008) Translational control by a small RNA: dendritic BC1 RNA targets the eukaryotic initiation factor 4A helicase mechanism. Mol Cell Biol 28:3008-3019.

Lin Y, Brosius J, Tiedge H (2001) Neuronal BC1 RNA: co-expression with growth-associated protein-43 messenger RNA. Neuroscience 103:465479.

Mader S, Brimberg L, Diamond B (2017) The role of brain-reactive autoantibodies in brain pathology and cognitive impairment. Front Immunol 8:1101.

Mikdashi J, Krumholz A, Handwerger B (2005) Factors at diagnosis predict subsequent occurrence of seizures in systemic lupus erythematosus. Neurology 64:2102-2107.

Muddashetty R, Khanam T, Kondrashov A, Bundman M, Iacoangeli A, Kremerskothen J, Duning K, Barnekow A, Hüttenhofer A, Tiedge H, Brosius J (2002) Poly(A)-binding protein is associated with neuronal BC1 and BC200 ribonucleoprotein particles. J Mol Biol 321:433-445.

Munro TP, Magee RJ, Kidd GJ, Carson JH, Barbarese E, Smith LM, Smith R (1999) Mutational analysis of a heterogeneous nuclear ribonucleoprotein A2 response element for RNA trafficking. J Biol Chem 274: 34389-34395

Mus E, Hof PR, Tiedge H (2007) Dendritic BC200 RNA in aging and in Alzheimer's disease. Proc Natl Acad Sci U S A 104:10679-10684.

Muslimov IA, Santi E, Homel P, Perini S, Higgins D, Tiedge H (1997) RNA transport in dendrites: a cis-acting targeting element is contained within neuronal BC1 RNA. J Neurosci 17:4722-4733.

Muslimov IA, Nimmrich V, Hernandez AI, Tcherepanov A, Sacktor TC, Tiedge H (2004) Dendritic transport and localization of protein kinase

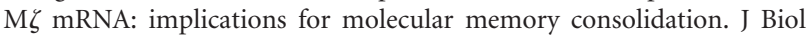
Chem 279:52613-52622.

Muslimov IA, Iacoangeli A, Brosius J, Tiedge H (2006) Spatial codes in dendritic BC1 RNA. J Cell Biol 175:427-439.

Muslimov IA, Patel MV, Rose A, Tiedge H (2011) Spatial code recognition in neuronal RNA targeting: role of RNA-hnRNP A2 interactions. J Cell Biol 194:441-457.

Muslimov IA, Tuzhilin A, Tang TH, Wong RK, Bianchi R, Tiedge H (2014) Interactions of noncanonical motifs with hnRNP A2 promote activitydependent RNA transport in neurons. J Cell Biol 205:493-510.

Muslimov IA, Eom T, Iacoangeli A, Chuang SC, Hukema RK, Willemsen R, Stefanov DG, Wong RKS, Tiedge H (2018) BC RNA mislocalization in the fragile X premutation. eNeuro 5:pii: ENEURO.0091-18.2018.

Noller HF (2005) RNA structure: reading the ribosome. Science 309: $1508-1514$.

Oostra BA, Willemsen R (2009) FMR1: a gene with three faces. Biochim Biophys Acta 1790:467-477.

Popescu A, Kao AH (2011) Neuropsychiatric systemic lupus erythematosus. Curr Neuropharmacol 9:449-457.

Qiao SW, Kobayashi K, Johansen FE, Sollid LM, Andersen JT, Milford E, Roopenian DC, Lencer WI, Blumberg RS (2008) Dependence of antibody-mediated presentation of antigen on FcRn. Proc Natl Acad Sci U S A 105:9337-9342.

Rhodes DA, Isenberg DA (2017) TRIM21 and the function of antibodies inside cells. Trends Immunol 38:916-926.

Robeck T, Skryabin BV, Rozhdestvensky TS, Skryabin AB, Brosius J (2016) BC1 RNA motifs required for dendritic transport in vivo. Sci Rep 6:28300.

Rozhdestvensky TS, Kopylov AM, Brosius J, Hüttenhofer A (2001) Neuronal BC1 RNA structure: evolutionary conversion of a tRNA ${ }^{\text {Ala }}$ domain into an extended stem-loop structure. RNA 7:722-730.

Schoch A, Thorey IS, Engert J, Winter G, Emrich T (2014) Comparison of the lateral tail vein and the retro-orbital venous sinus routes of antibody administration in pharmacokinetic studies. Lab Anim 43:95-99.

Schur PH, Monroe M (1969) Antibodies to ribonucleic acid in systemic lupus erythematosus. Proc Natl Acad Sci U S A 63:1108-1112.

Skryabin BV, Kremerskothen J, Vassilacopoulou D, Disotell TR, Kapitonov VV, Jurka J, Brosius J (1998) The BC200 RNA gene and its neural expression are conserved in Anthropoidea (Primates). J Mol Evol 47: 677-685.

Sturgill BC, Carpenter RR (1965) Antibody to ribosomes in systemic lupus erythematosus. Arthritis Rheum 8:213-218.

Suzuki T, Ishii-Watabe A, Tada M, Kobayashi T, Kanayasu-Toyoda T, Kawa- 
nishi T, Yamaguchi T (2010) Importance of neonatal FcR in regulating the serum half-life of therapeutic proteins containing the fc domain of human IgG1: a comparative study of the affinity of monoclonal antibodies and fc-fusion proteins to human neonatal FcR. J Immunol 184: $1968-1976$.

Talal N (1973) Antibodies binding 3H-reovirus RNA in systemic lupus erythematosus. Clin Immunol Immunopathol 1:230-233.

Tan EM, Cohen AS, Fries JF, Masi AT, McShane DJ, Rothfield NF, Schaller JG, Talal N, Winchester RJ (1982) The 1982 revised criteria for the classification of systemic lupus erythematosus. Arthritis Rheum 25: $1271-1277$

Tiedge H (1991) The use of UV light as a cross-linking agent for cells and tissue sections in in situ hybridization. DNA Cell Biol 10:143-147.

Tiedge H, Fremeau RT Jr, Weinstock PH, Arancio O, Brosius J (1991) Dendritic location of neural BC1 RNA. Proc Natl Acad Sci U S A 88: 2093-2097.

Tiedge H, Chen W, Brosius J (1993) Primary structure, neural-specific expression, and dendritic location of human BC200 RNA. J Neurosci 13: 2382-2390.

Uccellini MB, Busto P, Debatis M, Marshak-Rothstein A, Viglianti GA (2012) Selective binding of anti-DNA antibodies to native dsDNA fragments of differing sequence. Immunol Lett 143:85-91.

Uchiumi T, Traut RR, Elkon K, Kominami R (1991) A human autoantibody specific for a unique conserved region of $28 \mathrm{~S}$ ribosomal RNA inhibits the interaction of elongation factors 1 alpha and 2 with ribosomes. J Biol Chem 266:2054-2062. van Venrooij WJ, Hoet R, Castrop J, Hageman B, Mattaj IW, van de Putte LB (1990) Anti-(U1) small nuclear RNA antibodies in anti-small nuclear ribonucleoprotein sera from patients with connective tissue diseases. J Clin Invest 86:2154-2160.

Vidovic I, Nottrott S, Hartmuth K, Lührmann R, Ficner R (2000) Crystal structure of the spliceosomal $15.5 \mathrm{kD}$ protein bound to a U4 snRNA fragment. Mol Cell 6:1331-1342.

Wang H, Iacoangeli A, Popp S, Muslimov IA, Imataka H, Sonenberg N, Lomakin IB, Tiedge H (2002) Dendritic BC1 RNA: functional role in regulation of translation initiation. J Neurosci 22:10232-10241.

Wang H, Iacoangeli A, Lin D, Williams K, Denman RB, Hellen CU, Tiedge H (2005) Dendritic BC1 RNA in translational control mechanisms. J Cell Biol 171:811-821.

Zhong J, Chuang SC, Bianchi R, Zhao W, Lee H, Fenton AA, Wong RK, Tiedge H (2009) BC1 regulation of metabotropic glutamate receptormediated neuronal excitability. J Neurosci 29:9977-9986.

Zhong J, Chuang SC, Bianchi R, Zhao W, Paul G, Thakkar P, Liu D, Fenton AA, Wong RK, Tiedge H (2010) Regulatory BC1 RNA and the fragile X mental retardation protein: convergent functionality in brain. PLoS One 5:e15509.

Zirkzee EJ, Steup-Beekman GM, van der Mast RC, Bollen EL, van der Wee NJ, Baptist E, Slee TM, Huisman MV, Middelkoop HA, Luyendijk J, van Buchem MA, Huizinga TW (2012) Prospective study of clinical phenotypes in neuropsychiatric systemic lupus erythematosus; multidisciplinary approach to diagnosis and therapy. J Rheumatol 39:2118-2126. 